\title{
A palace under the olive trees. Investigating the spatial organization of the Mycenaean palatial center at Ayios Vasileios (Laconia, Greece) through large-scale magnetic gradiometry
}

\author{
Wieke de Neef ${ }^{1,2} \cdot$ Sofia Voutsaki ${ }^{2} \cdot$ Burkart Ullrich $^{3} \cdot$ Ronald Freibothe $^{3}$
}

Received: 29 August 2021 / Accepted: 19 January 2022 / Published online: 28 January 2022

(c) The Author(s) 2022

\begin{abstract}
The results of a large-scale magnetometry survey are used to investigate two key aspects of the spatial organization of the Mycenaean palatial settlement at Ayios Vasileios (Laconia, Greece): the extent of the site and the existence, or possibly even zoning of distinct functional areas. These include the palatial core, funerary zones, industrial areas, and infrastructure. The unique situation at Ayios Vasileios, which remained relatively undisturbed after its abandonment, provides the possibility to explore the potential, limitations, and challenges of spatial research based on geophysical data of a prehistoric urban context. We do so by engaging different sources of information: geophysical contrasts mapped by our own and previous surveys, information from the excavations of the palatial core and the adjacent North Cemetery, preliminary observations on surface materials, and wider scholarship on Mycenaean palatial settlement. This dialogue between the disciplines enables us to problematize the interpretation of non-invasive geophysical prospection data and to check our implicit assumptions. Taking into account the different resolutions of these interdisciplinary sources, we formulate hypotheses about the layout and organization of the site which we hope to substantiate in the future by comparing against the surface data and the progress of the excavation.
\end{abstract}

Keywords Magnetic gradiometry $\cdot$ Greece $\cdot$ Late Helladic archaeology $\cdot$ Data interpretation $\cdot$ Spatial organization

\section{Introduction}

In this paper, we explore how large-scale geophysical surveys can support the reconstruction of the spatial organization of a Late Bronze Age palatial settlement in mainland Greece. Geophysical techniques are firmly established tools in the detection of archaeological traces, yet the resulting data are rarely used beyond the mere mapping of sites or to guide excavations. Geophysical data rarely have the precision or resolution of ground plans of excavated areas (Benech 2007), and their interpretation is difficult, as it

Wieke de Neef

wieke.deneef@ugent.be

1 Department of Archaeology, Ghent University, St-Pietersnieuwstraat 35, 9000 Ghent, Belgium

2 Groningen Institute of Archaeology, University of Groningen, Poststraat 6, 9712 ER Groningen, the Netherlands

3 Eastern Atlas GmbH \& Co. KG, Berliner Str. 69, 13189 Berlin, Germany requires both technical abilities and operator skill, thorough understanding of an infinite range of environmental factors, as well as a solid knowledge of the archaeological remains studied. Yet geophysical surveys nowadays can cover far more ground than excavations ever will, can provide information on a very different scale, and can contextualize more limited excavations in a more efficient and less costly way. In this paper, we argue that we can use large-scale geophysical survey data in order to reconstruct the extent and spatial organization of prehistoric urban sites by using Ayios Vasileios, a recently discovered palatial Late Bronze Age site in mainland Greece as case study. However, we also stress that we can only do so, if we integrate geophysical results and archaeological information, and if we establish a dialogue between the two disciplines.

Some caveats are necessary: prehistoric sites present particular challenges for non-invasive prospection methods because of their long occupation history, poor preservation, irregular lay-out, and low geophysical contrasts, which hinder the interpretation of geophysical data. The suitability of geophysical techniques for spatial research 
has been demonstrated for historical (urban) contexts (Seren et al. 2004; Corsi et al. 2012; Verdonck et al. 2020); Benech (2007) even performed a detailed spatial syntax analysis of domestic spaces in Hellenistic Dura-Europos (Syria) on the basis of magnetometer surveys. As this level of detail is rarely recovered in prehistoric contexts in the Mediterranean and beyond, and fewer prehistoric sites are investigated through non-invasive techniques (and have the results published) than sites from later periods, this uneven coverage persists. Nevertheless, there are positive examples where the internal organization of prehistoric settlements has been reconstructed on the basis of prospection data, such as the Neolithic ditched villages in the Italian Tavoliere plateau (Gallo et al. 2011) and the vast Neolithic centers of the Ukranian Trypillia culture (Chapman et al. 2014).

Why, then, have such large-scale non-invasive studies not been conducted before at the so-called palaces of the Late Helladic period in the Greek mainland (see chronological overview in Table 1), whose level of urbanization and monumentality seem favorable to geophysical prospection? We believe that research on such sites is hampered by their biographies and research histories. At the center of early archaeological interest, some palatial complexes (that is, the palace itself at the center of a larger settlement) suffer from poor nineteenth-century excavation or poor preservation, such as Mycenae; others lie buried under historical cities, such as Thebes or Athens. Moreover, the settlements surrounding the palaces have not been investigated systematically (Voutsaki et al. 2019). Only recently has more extensive research been carried out in Mycenaean towns, e.g., at the site of Pylos (Davis et al. 2017) and Iklaina (Cosmopoulos 2016) in Messenia (SW Peloponnese) or Dimini in Thessaly (Adrymi-Sismani 2016). Previous geophysical work in Dimini (Sarris et al. 2002) and other Mycenaean centers show the potential of non-invasive prospection in the study of Mycenaean towns, but so far, no palatial settlement has been extensively explored by geophysical survey to allow reconstructions of their spatial organization and functional layout. As a result, our understanding of the organization of Mycenaean political and economic centers is still based

Table 1 Chronology of the Bronze Age on the Greek mainland and the abbreviations used in the text

\begin{tabular}{llr}
\hline Phase & Abbreviation & \multicolumn{1}{l}{ Chronology } \\
\hline Early Helladic & EH & Ca. 3100-2100/2050 BC \\
Middle Helladic & MH & Ca. 2100/2050-1700 BC \\
Late Helladic I & LH I & Ca. 1700-1635 BC \\
Late Helladic II & LH II & Ca. 1635-1420 BC \\
Late Helladic IIIA-B & LH IIIA-B & Ca. 1420-1200 BC \\
Late Helladic IIIC & LH IIIC & Ca. 1200-1050 BC \\
\hline
\end{tabular}

on generalizing models which downplay differences in their size, complexity and developmental trajectories.

In this paper, we report new geophysical research conducted in 2018 at and around the Mycenaean urban center of Ayios Vasileios in Laconia (Greece). Because of its relatively recent discovery, limited later occupation and relatively good preservation, Ayios Vasileios offers a unique opportunity to map a near-complete Late Bronze Age palatial settlement using non-invasive prospection techniques. Moreover, it provides the possibility to explore the potential, limitations, and challenges of spatial research based on geophysical data from a prehistoric urban context. To do so, we have to engage in a dialogue between what we already know about Mycenaean palatial sites and the much coarser results of our geophysical surveys, both when interpreting detected features and when discussing their spatial interrelations. This dialogue between the disciplines involved enables us to problematize the interpretation of non-invasive geophysical prospection data and to check our implicit assumptions. Our aim is to be as explicit as possible in our interpretation of a large-scale magnetometry dataset by following a classification scheme for individual features, while at the same time using environmental, topographical, geophysical, and archaeological background information to formulate hypotheses about the layout of the site. To do so, we must first contextualize our work by briefly introducing the site of Ayios Vasileios and providing some information on Mycenaean palatial centers. We will then describe our methodology, as it developed on the basis of previous geophysical research at Ayios Vasileios, and present the research questions, challenges, and results of the 2018 magnetometer survey. We will finally present our ideas on two spatial aspects of Ayios Vasileios: the extent and functional zoning of this unique site. The result may not be as detailed as a spatial syntax analysis of the built environment of a historical city, but we can provide a first overview of the spatial characteristics of Ayios Vasileios and place these in the wider debate about the formation and operation of the Mycenaean palatial system. Needless to say, our interpretations will need to be groundtruthed by further excavation.

\section{Ayios Vasileios and Mycenaean palatial centers}

The archaeological site of Ayios Vasileios is situated on a low ridge in the basin of the river Eurotas in the region of Laconia in the southern Peloponnese, ca. $12 \mathrm{~km}$ south of the city of Sparta and $4 \mathrm{~km}$ east of the village of Xirokambi (Fig. 1). The ridge consists of calcareous marls intercalated with marly limestone interbeds, covered by $1-2-\mathrm{m}$-thick conglomerates. These formations dip towards the EastSoutheast, resulting in gentle slopes on this part of the hill. 


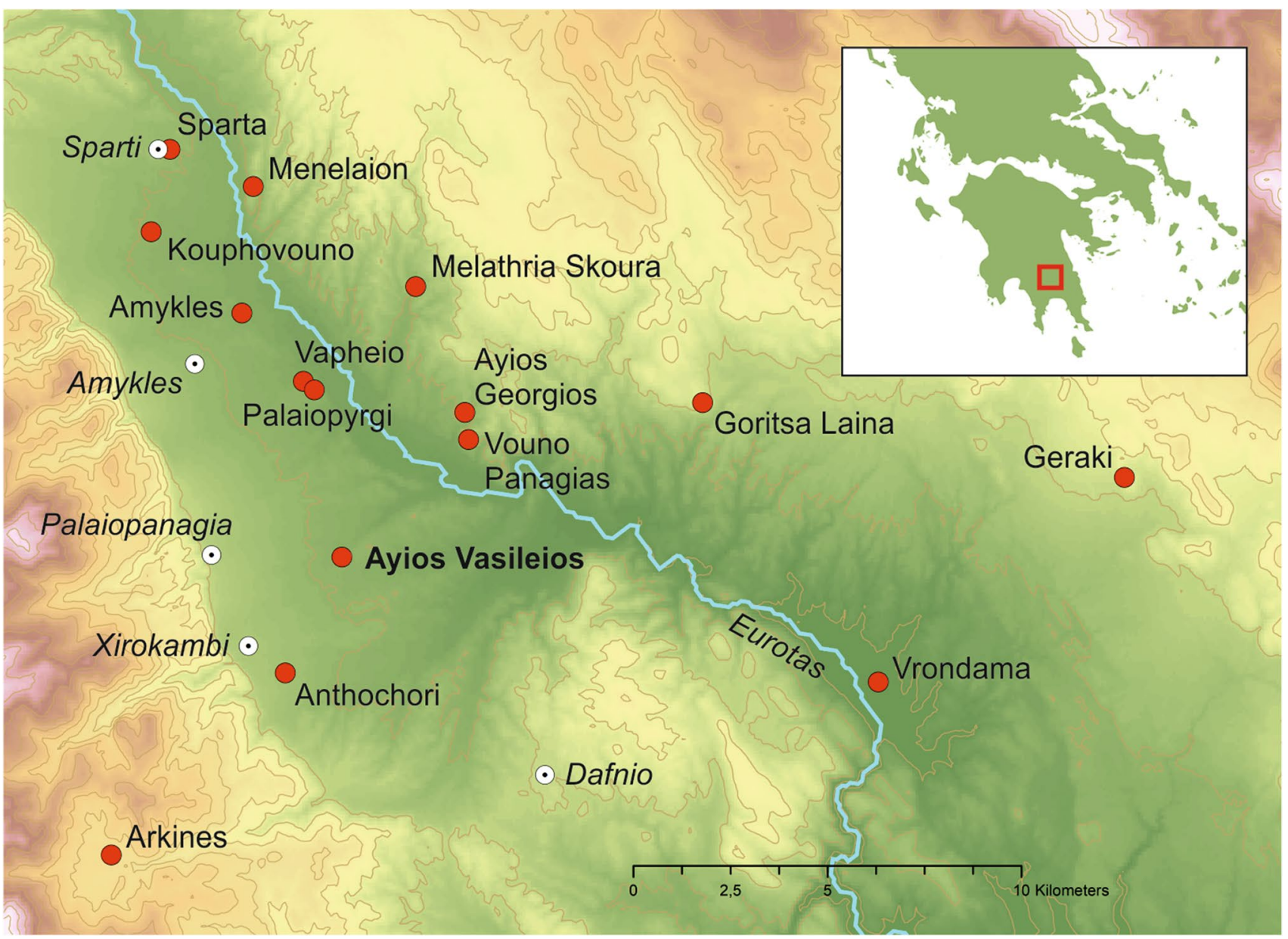

Fig. 1 The location of Ayios Vasileios and other known Mycenaean sites (red dots) in Laconia, Greece. Present-day towns are indicated with a white dotted circle. Background: DEM in $30 \mathrm{~m}$ resolution (SRTM, NASA)

The remarkably steep slopes on the North-Northwestern side of the ridge are presumably formed by the incision of the Rassina creek, a tributary of the Eurotas which originates in the Taygetos range, in conjunction with fault lines in this direction (Polymenakos 2012a). Just east of the palatial core the ridge is cut by the modern Sparta-Gytheio road, which probably damaged part of the settlement. The site is named after the small chapel located on its highest point.

The archaeological significance of Ayios Vasileios has long been recognized, but only recently has it been identified as the political center of Mycenaean Laconia (Vasilogamvrou 2010, 2011, 2012, 2013, 2016; Voutsaki et al. 2019). Since the first archaeological observations in the 1950s (Waterhouse and Hope Simpson 1960) and further non-systematic explorations in the 1990s (Banou 1996), Ayios Vasileios was known as a considerably sized settlement occupied in the Mycenaean period, with ephemeral traces of earlier occupation found in the area around the chapel. Banou estimated its extent as 20-30 hectares on the basis of the surface artifact distribution (Banou 1996: 100), but this figure was challenged by Hope Simpson (2009: 323 and note 5) who pointed to the effect of post-depositional processes such as deep ploughing. Nevertheless, the ridge was considered to be of some importance although it never was a serious candidate for the role of the political centerthe "palace" - of Mycenaean Laconia. This changed when a Linear B clay tablet was found accidentally during agricultural work in 2008. Immediate rescue operations by the Laconia Ephorate revealed that it came from a LH III dump in a collapsed rock-cut tomb some $300 \mathrm{~m} \mathrm{SW}$ of the chapel (location in Fig. 2); two further tablet fragments were found nearby on the surface (Vasilogamvrou 2010; Aravantinos and Vasilogamvrou 2012). Linear B tablets were the administrative records of Mycenaean states and were typically kept in palatial archives. Previously, the search for the Laconian palatial center had focused on the Menelaion site near Sparta where early mansions and a sizeable settlement have been excavated. Other candidates are Palaiopyrgi near the monumental tholos tomb at Vapheio or Pellana in north Laconia. Yet neither Linear B tablets nor monumental buildings or 


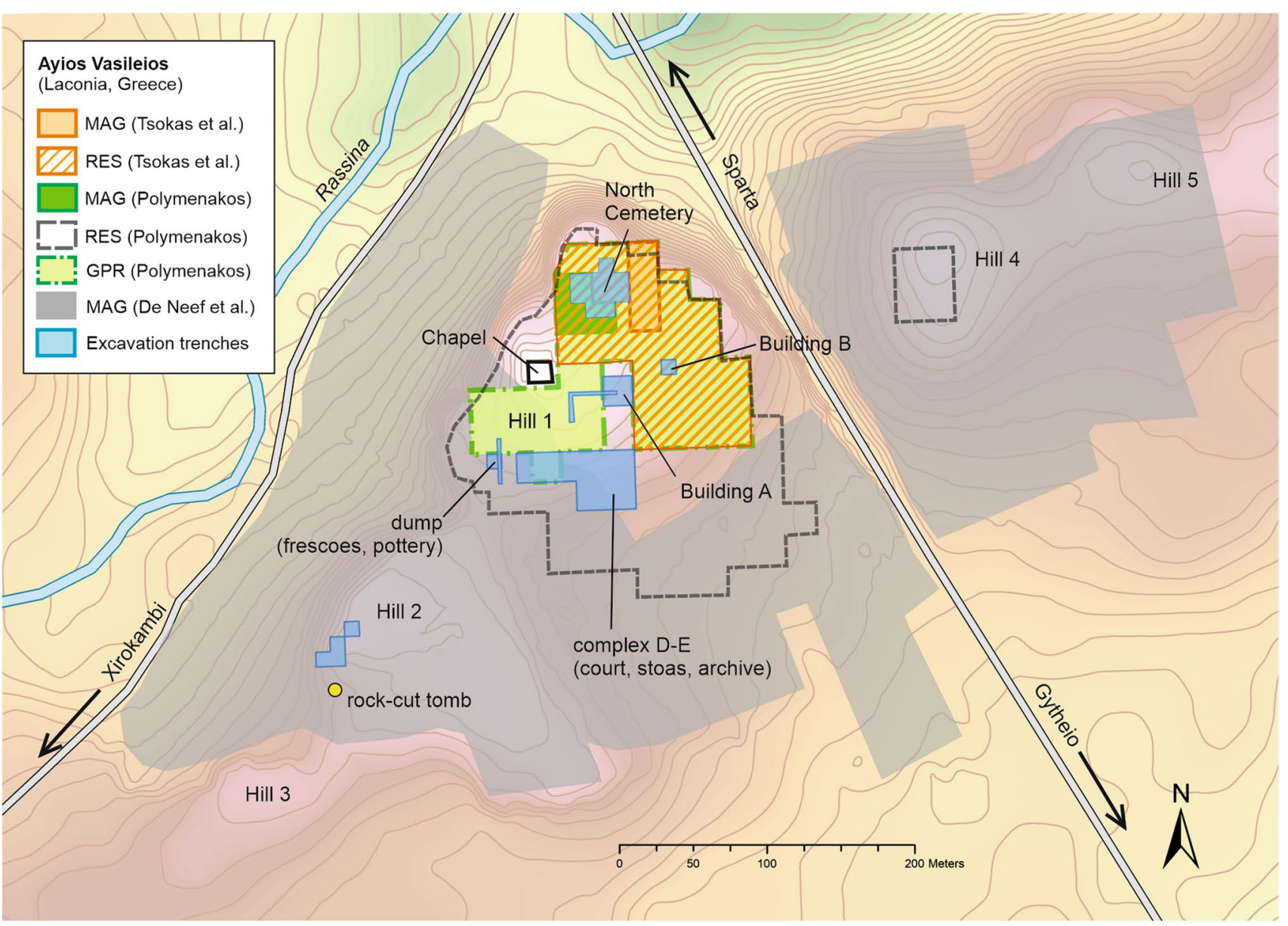

Fig. 2 Ayios Vasileios, Laconia, Greece. Overview of the areas investigated by excavations and geophysical surveys, 2010-2018, based on Tsokas et al. (2010; 2012a) and Polymenakos (2012a, b). Background

valuable artifacts have been found at these sites, although Palaiopyrgi has not been excavated extensively to date (Hitchcock 2018) and Pellana only partially (Spyropoulos 2013).

The Ayios Vasileios tablets gave a new impulse to the search for a palace. Systematic excavations and exploratory geophysical surveys under the auspices of the Archaeological Society at Athens were undertaken from 2010 onwards (Vasilogamvrou 2010; 2011; 2012; 2013; 2016; Tsokas et al. 2012a). Between 2010 and 2014, these were accompanied by detailed geophysical mapping of the site core using multiple techniques, the results of which have not been fully published as yet (Tsokas et al. 2010, and Polymenakos 2011, 2012a, b, 2013, 2014; see Polymenakos 2019 for the North Cemetery area). The excavations revealed a densely built settlement with monumental structures and exceptional finds, including a minor archive of Linear B tablets in a monumental building complex surrounding a very large courtyard. The systematic excavations and material studies continue to this day, but the discovery of an archive of Linear B tablets is a DEM based on topographical work by Erwin Bolhuis (GIA) and the GPS data of the magnetometry survey

firmly strengthens the candidacy of Ayios Vasileios as the administrative center of Mycenaean Laconia.

The identification of a new (possible) palatial center in Laconia puts a spotlight on many open questions in Mycenaean archaeology. Palatial centers are complex organizations at the apex of political, social, economic, and religious systems and have received much attention, yet many aspects remain obscure due to traditional and persistent research biases. The evidence from the Linear B tablets rightly attracts a lot of attention-but they describe only the last few months of the economic life of the palaces. As we pointed out above, archaeological research focuses on the palatial complexes or the monumental architecture, leaving the surroundings of the citadels underexplored. As a result, archaeologists still know little about the extent, demarcation, and spatial organization of the towns surrounding them.

Recent work suggests that there is no blueprint for these aspects among the known examples throughout mainland Greece (Voutsaki et al. 2019). Mycenaean palatial centers seem to vary in size, but the problems mentioned above 
make it difficult to reach firm conclusions and estimates for the same site vary considerably: The extent of Mycenae has been estimated from 48 (Whitelaw 2017: 124-127) to 32 ha (French 2002: 64) and of Pylos from 15 (Bennet 2007) to 25 ha (Whitelaw 2017: 124-127). Some palaces, such as Mycenae and Tiryns, are surrounded by massive fortification walls (Hope Simpson and Hagel 2006) whereas the existence of such a defensive feature at the Palace of Nestor at Pylos is still disputed (Blegen et al. 1973; Davis 1998; Bennet 2007; see also Hope Simpson and Hagel 2006, 52-53 and Zangger et al. 1997; we return to this point below). Evidence for functional specialization can be seen in the relation between settlements and cemeteries which are as a rule placed outside and at a distance of the built area. Functional specialization within the built area is poorly understood, because, as we stressed above, few palatial settlement sites are extensively excavated. For instance, it is not always easy to detect patterns in the placement of workshops or industrial areas. Workshops using prestige materials seem to be placed inside the citadels and near the palaces (e.g., in Mycenae and Thebes), indicating close ties to the palatial bureaucracy (Voutsaki 2001; Pullen 2013; Blegen and Rawson 1966). However, the distribution of pottery kilns or metal furnaces imply that other materials (perhaps less valuable?) were processed in different areas: near residential areas (e.g., in Tiryns: Dragendorff 1913: 339-341; Müller 1930: 113; Brysbaert 2014), in designated "potters' quarters" (e.g., in Miletus: Niemeier 1997), sometimes in the margins of the built-up area (e.g., in Dimini: AdrymiSismani 2013: 163-174). Recent studies also stress regional trajectories in the rise, expansion, and fall of palatial sites (Pantou 2010; Voutsaki et al. 2019).

To return to Ayios Vasileios, its extent will be explored below by means of geophysics, but the excavations at the site already indicate that the settlement may not have extended beyond the North Cemetery to the north and an isolated rock-cut tomb (so-called chamber tomb) to the southwest (see Fig. 2). In addition, the discovery of a deposit of fresco fragments and other materials to the southwest (Trench II: Vasilogamvrou 2010: 67; Kardamaki 2017; location indicated in Fig. 2) may give us additional evidence about the extent of the settlement, if we assume that these materials were dumped outside the built-up area. While traces of a circuit wall were reported in the early surveys (Waterhouse and Hope Simpson 1960: 79), the recent excavations have refuted the existence of fortifications around the site core. The excavations have revealed that Ayios Vasileios differs also in other respects from other palatial centers: Unlike Mycenae, Tiryns, or Pylos, Ayios Vasileios does not seem to have been occupied throughout the Early and Middle Bronze Age, and the palatial complex was probably built later and destroyed earlier than all other known Mycenaean palaces
(Vasilogamvrou 2011: 67; Kardamaki 2017; Voutsaki et al. 2019).

After its abandonment before the end of the Mycenaean period, Ayios Vasileios was later occupied only during the Byzantine period. While the Byzantine occupation has caused damage to the Mycenaean remains, this damage is relatively limited if one compares the site with other main centers (Thebes, Athens, Argos, etc.) which remained in use to the present day. The limited impact on the archaeological record of Ayios Vasileios offers an unprecedented opportunity for the application of modern research techniques on a near-complete settlement, particularly with the period of interest just below the surface. Moreover, the short occupation of the site, as attested by the excavations and the surface artifact survey (from MH III to LH IIIC early, but with a clear peak in LH IIIA), allows the analysis of the intra-site lay-out as a more or less contemporary complex with minimal impact from later occupation.

These considerations led in 2016 to the start of the 5-year Ayios Vasileios Survey. ${ }^{1}$ This project has three broad aims: the reconstruction of extent and lay-out of the palatial settlement through non-invasive prospection techniques, the assessment and refinement of prospection methodologies for complex prehistoric sites, and a better understanding of recent land use strategies and their impact on the preservation and detectability of archaeological remains (Voutsaki et al. 2019). These broad historical and methodological aims are addressed through three sub-projects whose results will be integrated: an archaeological fieldwalking survey (Wiersma et al. 2021), an ethnographic study of traditional land use and local perceptions of the (distant) past, and the geophysical survey of the site and its surroundings. In this paper, we focus on the results of the geophysical survey, and will refer only briefly to the tentative conclusions of the pedestrian survey, as the surface data are still being processed.

\section{Previous geophysical research at Ayios Vasileios and other Mycenaean sites}

Geophysical surveys are helpful in addressing some of the questions regarding the Ayios Vasileios settlement. Our current geophysical research focuses on three spatial aspects of the settlement: its extent, the demarcation of the whole or parts of the site, and the identification of functional areas.

\footnotetext{
1 The Ayios Vasileios Survey (2016-2021) is directed by Sofia Voutsaki, University of Groningen and Adamantia Vasilogamvrou, Director Emerita of the Laconia Ephorate. It is part of the overarching Ayios Vasileios Project which includes the ongoing excavations, and is conducted under the auspices of the Archaeological Society of Athens.
} 
Our main questions therefore are: Can we reconstruct the size, extent, and boundaries of the site? Can we detect functional specialization-e.g., burial, industrial, or refuse areas-in the settlement area? Can we detect infrastructural elements, e.g., points of access, roads or terracing? Do we have evidence for the regulation of space in Ayios Vasileios?

While only few Mycenaean palatial complexes have been investigated by geophysical techniques, these sporadic studies demonstrate that such late prehistoric contexts can be detected and mapped with non-invasive prospection methods. At Mycenae, ground-penetrating radar (GPR) was used to investigate terraces outside the citadel, resulting in the detection of linear features probably related to habitation contexts of a "Lower Town" surrounding the citadel (Maggidis and Stamos 2006). A similar "Lower Town" of the Palace of Nestor at Pylos was investigated using magnetometry, EM induction, and resistivity surveys. Here, the magnetometry proved to be especially successful in mapping several (semi-) rectangular and circular features, as well as a large linear feature which was perhaps related to a defensive system (Zangger et al. 1997; see also above). Magnetometry was also employed at the Mycenaean center at Iklaina, revealing a dense cluster of rectangular buildings and probably part of the settlement destroyed by fire (Boyd 2016). Further encouraging examples of geophysical prospection at other contexts include the town surrounding the palatial complex at Dimini (Sarris et al. 2002), the Mycenaean fortress of Gla (Maggidis 2010), the hydraulic management systems in the polder surrounding Gla (Lane et al. 2016), and the multi-method prospections of the densely settled Bronze and Iron Age site of Mitrou (Tsokas et al. 2012b). An early application of magnetometry alongside the excavations at the Menelaion near Sparta in 1974 and 1975, however, was not found to be helpful in locating archaeological remains, despite the detection of possible wall remains south of the excavation (Jones 2009). However, most of these investigations have been limited or partial and have not systematically addressed the questions we raise in this paper.

In contrast, Ayios Vasileios has been investigated since 2010 systematically using a broad suite of geophysical methods (see Voutsaki et al. 2019: Fig. 2 for an overview). A pilot study in 2010 consisted of magnetometry and electrical resistivity tests in the areas surrounding the rescue excavations (Tsokas et al. 2010; 2012a). Magnetic susceptibility readings of different materials on site led the team to be cautious about the potential of magnetometry for the mapping of Ayios Vasileios: limestone was found to produce magnetic contrasts with the local soils, but other materials such as schists appeared less distinct (Tsokas et al. 2010). However, non-structural features such as fills and refuse heaps with potentially strong magnetic contrasts were not considered, partly because these had not yet been identified in the excavations. A small area of $20 \times 60 \mathrm{~m}\left(1200 \mathrm{~m}^{2}\right)$ in the northern part of the site was investigated using a Geoscan FM256 fluxgate gradiometer, the results of which were found to be uninformative (location in Fig. 2: orange area labelled MAG Tsokas et al.). Yet in retrospect, these data proved to be useful for the development of the current survey strategy, as will be discussed below. In 2012, a geological study of the site and its surroundings indeed confirmed that the walls of the palace complex (and the North Cemetery graves) consist of various rock types, including limestone, quartzite, chert, schists and phyllites, and conglomerates, which raises questions about their detectability using magnetometry (Polymenakos 2012b).

After the 2010 pilot study, a series of GPR and resistivity mapping (RES) surveys were conducted on the central hill near the chapel. The 2010 RES tests covered $2920 \times 20 \mathrm{~m}$ units $\left(11,600 \mathrm{~m}^{2}\right)$ with a twin-probe array, which revealed alignments of high resistivity anomalies in rectangular shapes (Tsokas et al. 2010; 2012a; location in Fig. 2: lined orange area labelled RES Tsokas et al.). The main orientation of these features is NE-SW; the dimensions and outline indicate the presence of archaeological structures. RES surveys were continued by Polymenakos in 2011 (ca. 15,600 $\mathrm{m}^{2}$ to the west and south of the chapel), 2012 (ca. $9200 \mathrm{~m}^{2}$ in the SE of the hill), and 2014 (ca. $1200 \mathrm{~m}^{2}$ of the cemetery area in the northern part of the hill, extent indicated in Fig. 2 by a dashed gray line labelled RES Polymenakos). These surveys revealed a dense lay-out of rectangular buildings in the southern and eastern parts of the center of the settlement site, while the north and west appeared to have been less intensively built-up (Polymenakos 2012a; Vasilogamvrou 2012, Pl. 53). It was initially suggested that archaeological remains may not have survived on the eroding hilltop with its outcropping bedrock, while the thicker soils of the southern slopes buried and preserved architectural remains better. However, these patterns in the presence and absence of structural features were later revealed to be part of the spatial organization of the hill: the northern zone is occupied by a cluster of graves of the so-called North Cemetery which are cut in the underlying natural gravel layers.

The detection of graves in the North Cemetery became the focus of geophysical work in 2012 and 2013. Several geophysical techniques were tested: VLF electromagnetic induction (VLF-EM), magnetometry, seismic tomography, and ground-penetrating radar (GPR). Although the data are generally difficult to interpret because of the complex geological and topographical situation, magnetometry emerged as the most suitable method to detect contrasts between rock-cut features and their fills under the local circumstances. Magnetic gradiometry readings of a small area showed that the magnetic contrast between the natural background and anthropogenic features is effective in detecting/distinguishing human impact (Polymenakos 2012a, b, 2013). Moreover, these data place the small 2010 
magnetometry test of Tsokas et al. in a different light: while they were probably expecting rectangular features, their survey took place on the border of the cemetery area, where, as we now know after seven excavation campaigns at the cemetery and nine at the palatial complex, such straight structural remains do not occur. In retrospect, the 2010 pilot magnetometry data (Tsokas et al. 2010; 2012a) fit well with the magnetometry data from the cemetery (Polymenakos 2014) and add further information on the occurrence of local cavities. This observation was crucial in the planning of the current geophysical work, which not only focuses on mapping standing architecture, walls, and terraces demarcating the palatial settlement, but also on more ephemeral traces of human activity in and around the site. These cumulative insights underline the importance of larger areas for the understanding and interpretation of geophysical data, and of ground-truthing to interpret anomalies as signatures for particular types of features.

The GPR data of the North Cemetery, obtained with a 250-MHz-antenna, showed many variations in the reflection amplitudes of subsurface features. Problematic for the interpretation of the GPR data were the varying depths of the bedrock in the cemetery area. While soils generally tend to be shallow here $(<30 \mathrm{~cm})$, local depressions and pockets with sediments of $1-1.5 \mathrm{~m}$ were also recorded, producing false positives (Polymenakos 2019). Moreover, the graves are filled with a mix of soil and rocks which masks the contrast between the grave and its surroundings. The situation is in fact even more complex, as some of the graves seem to have been dug into a much larger artificial cavity (Voutsaki et al. 2021) which had been filled in with local re-deposited materials, resulting in widely heterogeneous fills in the central cluster.

Together with these previous geophysical surveys and methodological insights, we can now use our present work to evaluate two key issues in the interpretation of geophysical data beyond the mere mapping of anomalies. These are based on the assumption that we can distinguish heavily eroded areas from relatively undisturbed soil records. Firstly, are magnetometry surveys suitable for the identification of expressions of regular (or even perhaps regulated?) spatial organization of the Ayios Vasileios hill, taking into consideration a broad range of potentially present features across a large area? Secondly, to what extent can we interpret the arrangement of features, occupied and "empty" areas in terms of possible functional specialization? These questions are crucial to our aim to establish the extent of the settlement, identify areas of different activities, and interpret them within the framework of existing scholarship on Mycenaean palatial settlements. These interpretative questions and research aims are used to structure the present geophysical work at Ayios Vasileios, which will be introduced next.

\section{Approach and method}

Two magnetic gradiometry surveys were conducted in spring and autumn 2018. The climate conditions were more or less similar during both campaigns, but more fields were accessible in autumn after mowing and the cutting of olive trees. We used a flexible LEA-MAX system (Eastern Atlas) consisting of a light-weight cart array with seven Förster FEREX CON650 fluxgate probes mounted at $0.5-\mathrm{m}$ interval (Fig. 3). While the cart is moved along parallel profiles at walking speed, the individual sensors measure the difference of the vertical component of the Earth's magnetic field between two vertically arranged fluxgate magnetometers designated as the "gradient", with a sensitivity of $0.1 \mathrm{nT}$ (nanoTesla). The difference between the readings in each set of sensors is used to map local variations at an in-line point resolution of $5 \mathrm{~cm}$ approximately, depending on speed.

The data was positioned using a differential GNSS set-up with a rover mounted on the cart and a fixed positioned base station. The relative accuracy of the RTKGNSS readings was $2 \mathrm{~cm}$, but GNSS reception under the olive trees varied. A very dense canopy poses problems, as we noticed on the southern slope at Ayios Vasileios. To counter this effect, we used the odometer (wheel marker) of the cart for additional positioning. The GNSS quality throughout each survey transect was controlled, and each line was started at a location where we obtained optimal RTK quality. We then used the odometer data to correct for those areas where GNSS reception quality was poor. Data processing included decoding, statistical drift correction, normalization, and gridding. The gridded data are a 2D representation of spatial patterning in near-surface contrasts in the difference of the vertical component of the Earth's magnetic field at a resolution of $25 \times 25 \mathrm{~cm}$ (Fig. 4).

The survey conditions at Ayios Vasileios required specialized data processing adapted to our survey approach suited to the specific situation on site. The crucial factors were a flexible coverage, with sensors being taken "out" in order to pass by olive trees, and the irregularities in GNSS reception under the canopy. In order to cover as much ground as possible, we used a flexible cart system of which the outer wings could be pulled in carefully when passing an olive tree. In this way, we could cover the open strips between the lines of trees as well as the tree intervals. The effect of sensor movement has an impact of one channel (of 7 in total) at a short distance of about $0.5 \mathrm{~m}$ which turned out to be negligible in most cases. This went well in large parts of the site and in the zone east of the Sparta-Gytheio road, where olive trees were planted in regular lines at ca. $5 \mathrm{~m}$ distance. The 3 -m wide cart 


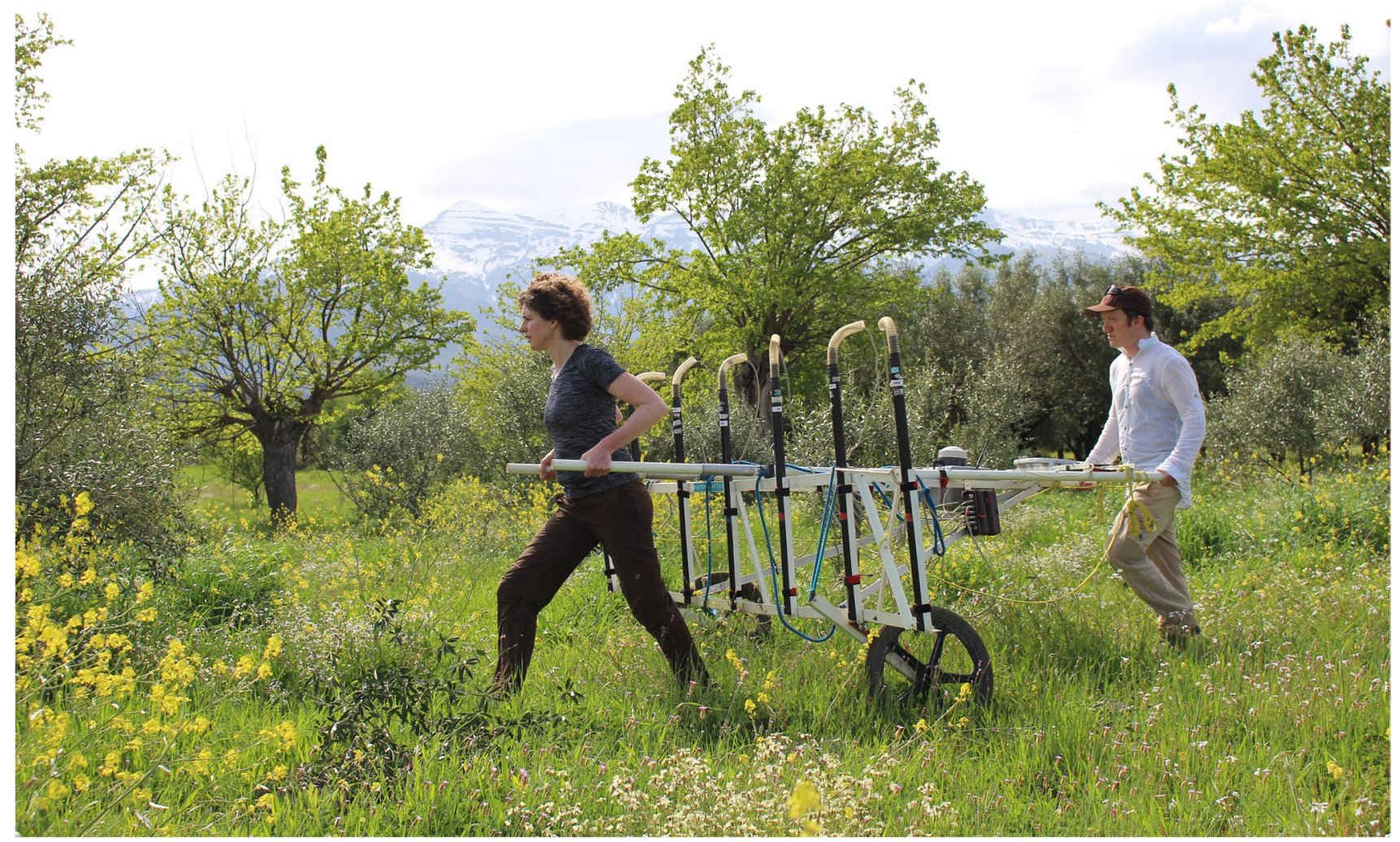

Fig. 3 Magnetometry survey at Ayios Vasileios in April 2018 (photo B. Ullrich)

was ideal for passing twice along these lanes including the intervals between the trees, with only minor overlap. However, some olive groves were more challenging, with irregularly planted trees and irrigation pipes hung from branches with metal hooks. These we removed or pulled out of the way if possible; a full coverage was only possible with some overlapping lines.

The magnetometry data was interpreted according to the morphological characteristics and magnetic properties of individual features. First, we distinguished three broad classes of features caused by (a) natural phenomena (gullies, outcropping conglomerate banks, etc.), (b) anthropogenic impact (all-period settlement and land use), and (c) modern metal disturbances (electricity poles, scrap metal, fences, etc.). This was done mainly by the size and shape of the anomalies, assigned to visible features, and, in the case of modern disturbances, additionally by their high magnetic amplitudes. We then proceeded to interpret the anthropogenic features in more detail by looking at their dimensions, location, configurations, orientation, and magnetic properties. The final classification scheme consists of eight types of magnetic features (Table 2). The interpreted data is presented in Figs. 5-8.

Throughout the discussion of the magnetometry results below, we will also briefly refer to the results of the surface survey, although we will base ourselves on preliminary conclusions (Wiersma et al. 2021, Wiersma et al. in press), as the data are still being processed. The full integration of the artifact and geophysical surveys will be done in the final publication of the Ayios Vasileios Survey project. In addition, in some cases, we can infer possible explanations for specific features from materials seen on the surface during the magnetometer survey, from observations in previous investigations of the site (Waterhouse and Hope Simpson 1960; Banou 1996) and from the on-going excavations, and we will draw on observations at other palatial sites. Unfortunately, we did not get permission to verify our interpretations through targeted coring or test pits, but we believe that by using all these different types of evidence and by being explicit about the way we reach our inferences in the discussion of the results, we offer a consistent and convincing interpretation of the evidence. 


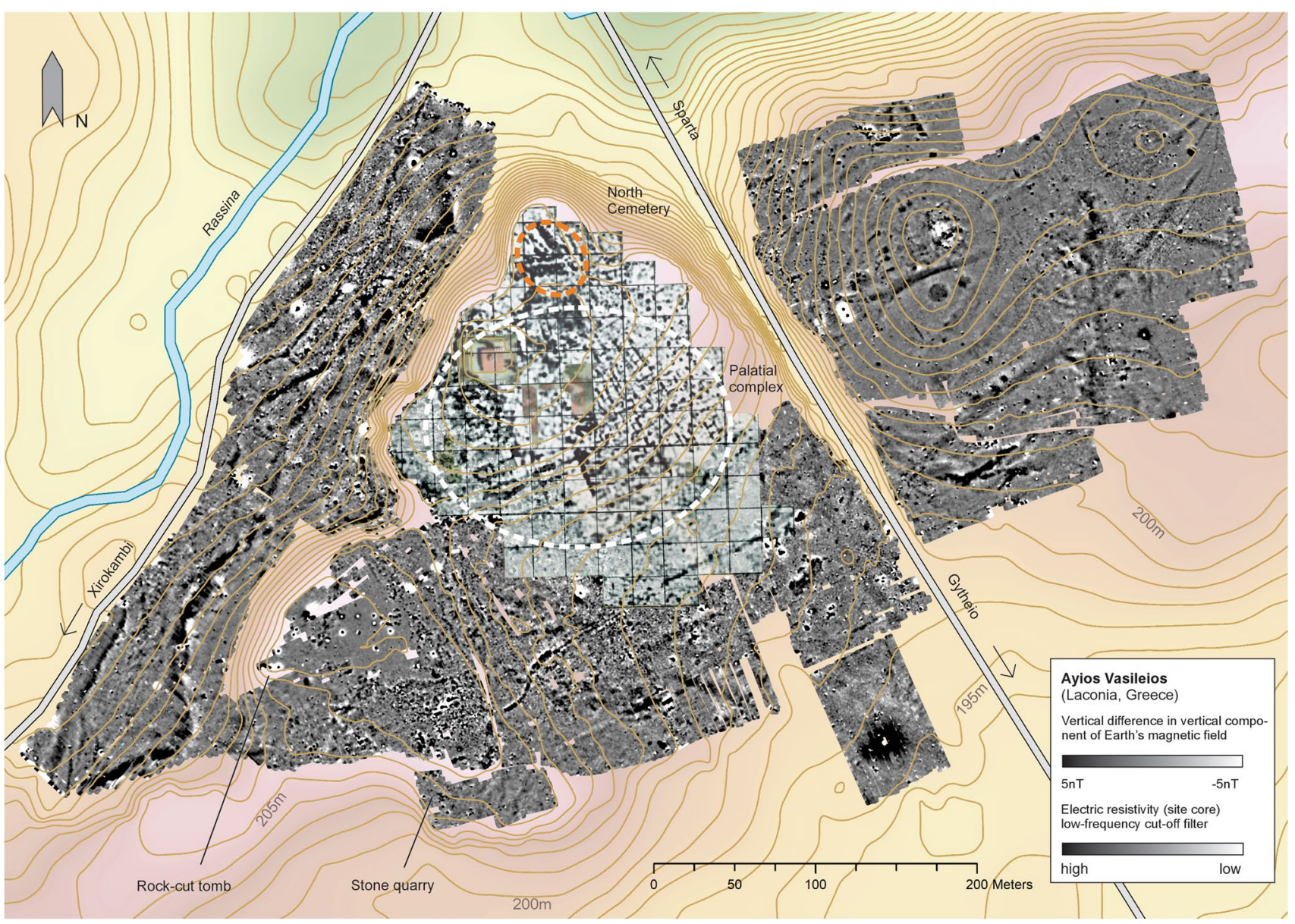

Fig. 4 Ayios Vasileios, Laconia, Greece. Overview of results of the 2018 magnetometry survey and the RES survey of the site core and North Cemetery (data from Tsokas et al. 2010, 2012a; Polymenakos 2012a, b; Vasilogamvrou 2012)

Table 2 Classification of magnetic features

\begin{tabular}{|c|c|c|c|c|}
\hline & Origin & Description & Typical cause for this type of magnetic feature & Visualization \\
\hline 1 & Modern disturbance & $\begin{array}{l}\text { Single or clustered anomalies based on strong } \\
\text { (ferromagnetic) magnetization }\end{array}$ & Metal parts: scrap metal, fences, pipeline & Light blue \\
\hline 2 & Natural & $\begin{array}{l}\text { Large single or multiple magnetic anomalies; } \\
\text { typically linear or sinuous }\end{array}$ & $\begin{array}{l}\text { Geological or soil formation (bedrock, faults, } \\
\text { erosion effects) }\end{array}$ & Green \\
\hline 3 & Anthropogenic/ancient & $\begin{array}{l}\text { Cluster of apparently related multiple magnetic } \\
\text { anomalies related to human impact, inferred } \\
\text { from their magnetic amplitudes }\end{array}$ & $\begin{array}{l}\text { Configuration of related features: house plan, } \\
\text { habitation or occupation zone; excavation area }\end{array}$ & Pink \\
\hline 4 & Anthropogenic/ancient & Linear feature with positive magnetization & $\begin{array}{l}\text { Linear features with fills: ditch, hollow road, } \\
\text { canal }\end{array}$ & Beige \\
\hline 5 & Anthropogenic/ancient & $\begin{array}{l}\text { Linear feature with negative or weakly positive } \\
\text { magnetization }\end{array}$ & $\begin{array}{l}\text { Linear features with building materials: walls, } \\
\text { terraces, foundations }\end{array}$ & Light brown \\
\hline 6 & Anthropogenic/ancient & $\begin{array}{l}\text { Single magnetic anomaly with positive ampli- } \\
\text { tudes }\end{array}$ & Features with fills: pits, postholes, dumps & Red \\
\hline 7 & Anthropogenic/ancient & $\begin{array}{l}\text { Single magnetic anomaly with strong positive or } \\
\text { dipole amplitudes }\end{array}$ & $\begin{array}{l}\text { Features with high (thermoremanent) magneti- } \\
\text { zation: burnt structures, kilns, ovens }\end{array}$ & Dark red \\
\hline 8 & Anthropogenic/recent & $\begin{array}{l}\text { Linear features with negative or weakly positive } \\
\text { magnetization that can be related to recent or } \\
\text { visible traces of land use }\end{array}$ & $\begin{array}{l}\text { Features with fills: plough marks, paths, ditches, } \\
\text { hole }\end{array}$ & White \\
\hline
\end{tabular}




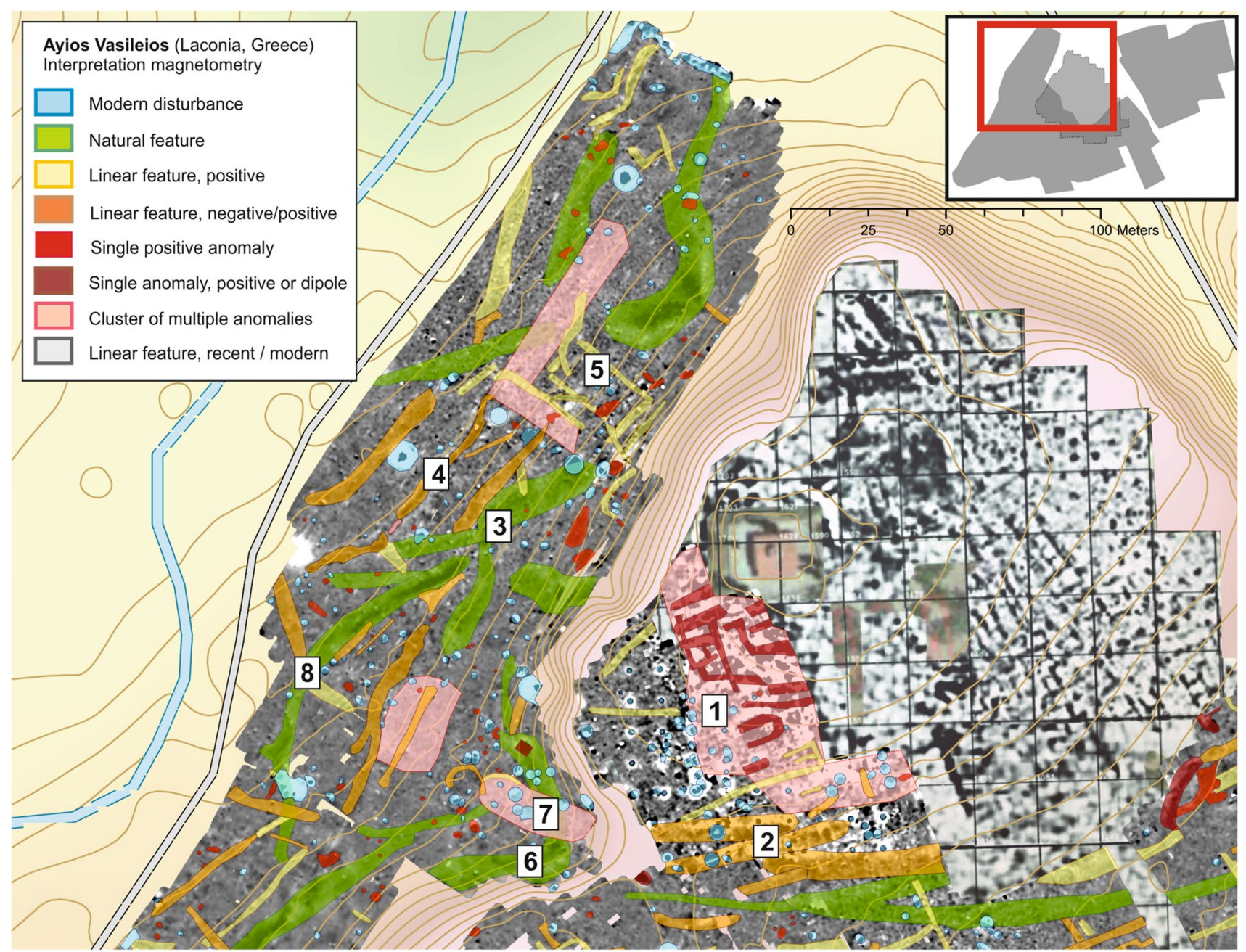

Fig. 5 Ayios Vasileios, Laconia, Greece. Interpretation of magnetometry results in the NW part of the site. The RES data of the site core are shown (after Tsokas et al. 2010, 2012a; Vasilogamvrou 2012; Polymenakos 2012a, b). Features discussed in the text are numbered

\section{Results}

We will present the results by examining the different parts of the site, starting from the NW. The investigated NW part of the densely occupied site core is characterized by features causing strong magnetic amplitudes, as well as disturbances by the cement measurement points of the excavation. The area with the highest amplitudes [1 in Fig. 5], with peaks reaching more than $\pm 150 \mathrm{nT}$, is situated near the chapel and is clearly demarcated. The high magnetic amplitudes point to remanent magnetized materials and are likely to be related to the burnt destruction of the palace complex, as attested in the excavated contexts. Some of the high dipole amplitude features show clear alignments which can be linked to structural remains (walls) already known from the RES survey maps. The site core is bordered to the south by a series of linear features
[2] which we tentatively interpret as terraces or walls because they coincide with marked steps in the slope.

The northwestern area is situated at the base of the steep north slope of the Ayios Vasileios ridge. This area is characterized by a series of linear features following the natural slope contours [3]. Some large curvilinear features may be caused by outcropping conglomerate banks, but particular straight and narrow linear features following the contours [4] are tentatively interpreted as man-made structures such as terraces. The data is generally noisy which has partly to do with the many disturbances of irrigation pipes, but there are also indications for past human impact close to the steep slope [5]. This is corroborated by the artifact survey which recorded a higher density of ancient material here although this belongs partly to later periods (Wiersma et al., in press). The magnetic data here are difficult to interpret, but the anomalies may be related to a limestone building, considering their weakly positive linear character. 


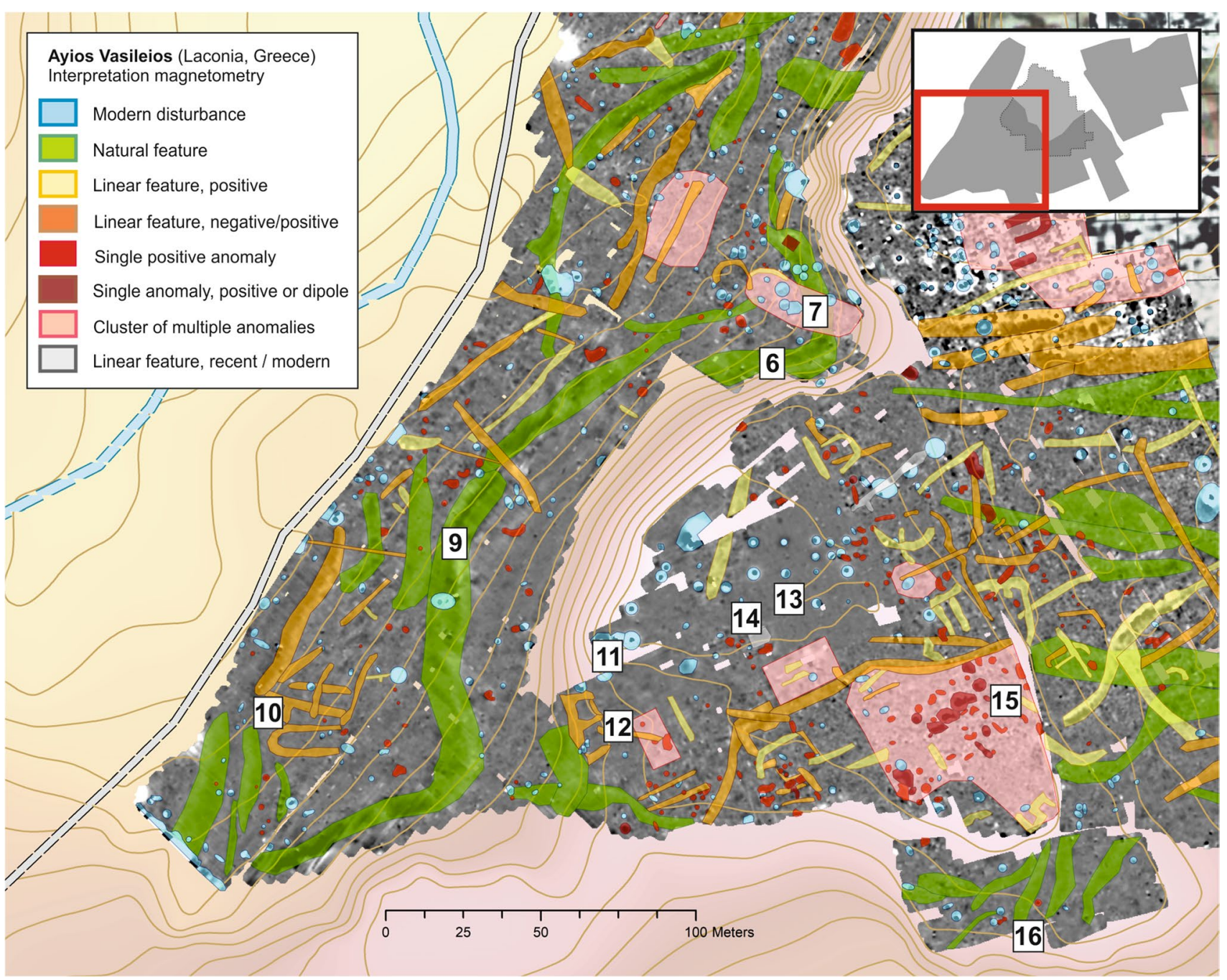

Fig. 6 Ayios Vasileios, Laconia, Greece. Interpretation of magnetometry results in the western part of the site. Features discussed in the text are numbered

The strip connecting the northwestern area with the pass between Hills 1 and 2 provides a natural access to the higher ridge. A remarkable curvilinear dipole anomaly [6] is likely to be caused by an outcropping conglomerate bank, yet it is cut by a noisy strip of ca. $15 \mathrm{~m}$ wide which may be related to the use of this natural access route [7]. Further down the slope, an area with linear, weakly negative magnetic amplitudes [8] intersects one of the large positive (we assume natural) linear features [3]. We tentatively interpret this zone as anthropogenic.

The western corner of the survey area is again characterized by curvilinear, dipole anomalies [Fig. 6, feature 9] which we interpret as natural geological phenomena like outcropping conglomerate banks. A flat zone at the bottom of the natural access to Hill 3 has some linear features with very weakly magnetic anomalies which may be related to (recent?) human impact [Fig. 6, feature 10]. The Mycenaean rock-cut chamber tomb found some $60 \mathrm{~m}$ east [11] is situated near the access route to Hill 2 and the plateau directly south of it. The single dipole anomalies in this area are related to the metal pins of the first trenches excavated in 2009 (Vasilogamvrou, 2010: 67-68; Pl. 44a). To the south and southwest of the tomb, we also detected linear features with a weak magnetic contrast and clusters of positive magnetic anomalies related to human impact [12]. Mycenaean cemeteries are often located along access routes to settlements.

The southern zone of Ayios Vasileios contains many archaeologically highly relevant features, but there is also an area that seems devoid of human impact. This "quiet" zone [Fig. 6, feature 13] is confirmed on the surface (Wiersma et al. in press). Moreover, test trenches in the first years of the excavation (which most likely produce the two rectangular positive magnetic anomalies [14]) revealed no Mycenaean layer in situ (Vasilogamvrou 2010: 66). It is therefore 


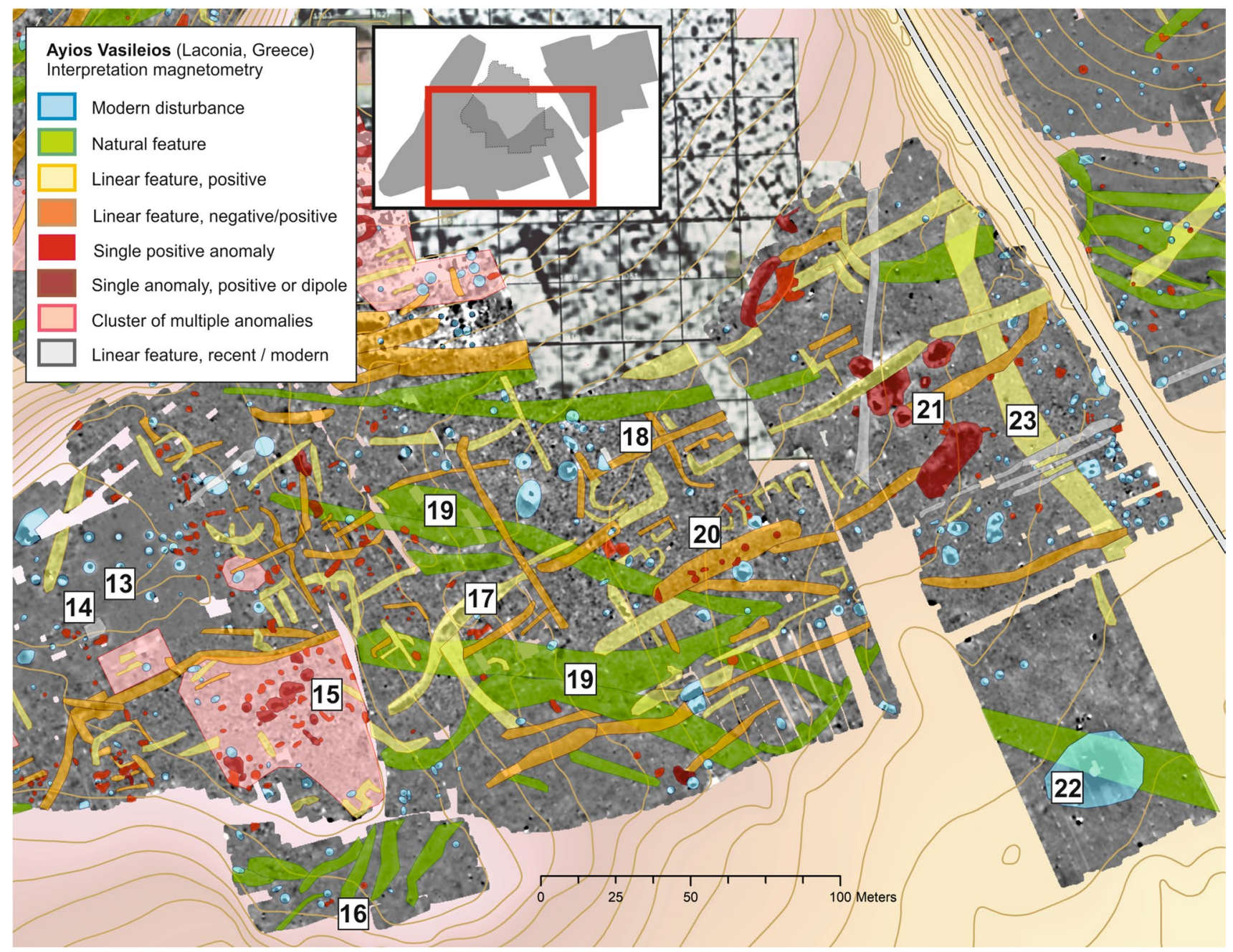

Fig. 7 Ayios Vasileios, Laconia, Greece. Interpretation of magnetometry results in the southern part of the site. The RES data of the site core are shown (after Tsokas et al. 2010, 2012a; Vasilogamvrou 2012; Polymenakos 2012a, b). Features discussed in the text are numbered

possible that in Ayios Vasileios, we see a confirmation of the general practice in Mycenaean settlements where single tombs (such as the rock-cut tomb [11]) or entire cemeteries are placed at a distance from the settlement. If we move further to the south-southeast, a concentration of magnetic anomalies with high amplitudes along a path in the south contains a number of tadpole-shaped, dipole anomalies with diameters of ca. $2 \mathrm{~m}$ for the positive values [15]. We interpret these anomalies as kilns with an oval oven pit and surrounding tapping pit or channel. This zone could be interpreted as workshop area; we will present corroborating evidence for this suggestion below, in Sect. 6.2. Further evidence for production in this southern zone comes from a stone quarry to the south of the path [16]. Magnetometry in the quarry area did not yield clear anthropogenic traces; it therefore seems that this stone working area was outside the settlement. Quarrying of conglomerate outcrops used both in the palatial complex and in graves also occurred on the margins of the palatial settlement, for instance, in the North Cemetery.

The south-central and southeastern zones contain a large amount of archaeologically relevant features. Conspicuous is a long linear dipole feature [Fig. 7, feature 17]. In the east, it ends in a right angle which could be interpreted as an entrance or gate. This is bordered by a zone of many small-scale magnetic anomalies [18]. Beyond this gap, the linear feature continues further to the northeast towards a zone of strongly magnetic dipole anomalies [21]. Access to the palatial settlement is easiest from the south, making use of the gentle slope on this side of the hill. If our interpretation is correct, it would imply that the site was oriented south, towards the coast, instead of towards the interior to the north. The linear feature [17] is ca. $7 \mathrm{~m}$ at its widest and appears to consist of three faces with two intermediate fills. Part of this feature was also recorded as a highresistance anomaly by RES (Fig. 4). We interpret this feature 
as a wall or terrace belonging to the archaeological site: it has the same orientation as the main buildings exposed in the palatial complex, including a heavily built drystone wall exposed in the excavations of Building D (Vasilogamvrou 2011: 62-64, Pl. 56a-b, 57a-b, 58a). As linear feature 17 does not follow the present-day slope contours, we do not think it is a (recent) agricultural terrace. Other, weaker linear features with the same orientation may also be part of the palatial settlement, while a series of low amplitude, NW-SE oriented linear anomalies may be produced by the underlying bedrock [19].

Just south of the large "wall" [17], a cluster of linear and small anomalies with positive amplitudes are interpreted as building remain and related features like pits or refuse dumps [20]. Remarkable strongly magnetic dipole anomalies in the SE could be attributed to workshop areas [21]. This suggestion is strengthened by the presence of metal slags on the surface, but as their date is uncertain, this has to remain a hypothesis. Although surface artifacts might help resolve this problem, the overall finds density in this part of the site was too low to give robust support-which suggests that we are reaching the borders of the settlement (Wiersma et al. 2021: 169; Wiersma et al. in press).

A linear feature running parallel to the modern SpartaGytheio road [23] may be related to an older road or pathway; we have not found indications of a path here on twentieth-century maps, and it therefore may be older, though we cannot say how much older. An open field in the SE revealed only few magnetically recognized features except for the disturbance of an electricity pole [22]; we think that this area must have been outside the settlement. If this is accepted, then the workshop/industrial areas [21] we have postulated above - if of course they belong to the Mycenaean periodmay have been located at the periphery of the settlement.

The eastern zone, on the other side of the Sparta-Gytheio road, contains several areas of very high archaeological relevance and a series of linear anomalies which may be caused by trackways, as well as curvilinear magnetic anomalies related to the local geology. If we start from the northwest part of this area, a cluster of magnetic anomalies is situated near the road cut [27]. Considering the finds on the surface including roof tiles, we associate their origin with a possible Classical/Hellenistic farmstead (Wiersma et al. in press). We interpret a cluster of magnetic anomalies on the north slope as traces of prehistoric (possibly Mycenaean) occupation [28]: during the magnetometer survey, we saw a recently dug illicit pit here with Mycenaean pottery on the surface.

On the highest point of the ridge, an ash heap of burnt olive tree cuttings causes a strong, circular dipole anomaly [Fig. 8, feature 24]. Surrounding this summit are seven spoon-shaped positive magnetic anomalies which we interpret as chamber tombs with entrances facing West and North [25]. Tombs with this shape, dimensions, and position in rows along the slope are typical for the Late Helladic/Mycenaean world. Another rock-cut tomb found to the southwest of the settlement belongs to the same type. If our interpretation is correct, then the position of this cemetery further away from the settlement cut into an adjoining hillslope conforms to general practice in the Mycenaean world.

Two circular, weakly positive magnetic features [26] of different size may also represent funerary structures which may be vaulted, stone-built tholos tombs, the elite tombs of the period. They share typical morphological and locational characteristics of tholoi: they have a regular, circular shape; they are set apart from other graves and have a panoramic view, in this case over the plain towards the south. While these features lack the typical long entrance passages, this may be a detection effect: in some cases, tholoi passages are not stone-built, but cut into the rock and filled with local soils after abandonment, in which case they would not produce a clear magnetic contrast. In the easternmost end of the survey area, the traces of a semi-triangular enclosure [29] were recorded, whose function is unclear. Further to the southeast, another circular anomaly with a diameter of approximately $6 \mathrm{~m} \mathrm{[30]}$ is visible in the data. The shape and dimensions of this feature, in combination with its location on a prominent position suggests that this, too, can be interpreted as a tholos tomb. If indeed it is a tholos, it may also have had a built passage, or at least this is how we could interpret the linear feature which starts from it and cuts against the slope towards the northeast. Interestingly, this feature is situated in a gap in otherwise very regular rows of olive trees; we can surmise that the spot was left open, because stones were encountered below the surface during the planting of olive trees. If this is accepted, we may go one step further and interpret the striking linear feature [31] as a track connecting the settlement with the cemeteries to the east (i.e., features [25], [26] and [30]). Indeed, Mycenaean cemeteries are often placed along roads leading to the settlement. The location, positioning, shape and orientation of the magnetically detectable features in this area support the interpretation of this area as a cemetery-however, this can only be confirmed by excavation.

\section{Discussion: the spatial organization of Ayios Vasileios}

In Sect. 3 above, we formulated two key issues in the interpretation of the magnetometry survey data at Ayios Vasileios that, if resolved, will allow to take this work beyond the mere mapping of buried features: first, the possibility to identify regular spatial organization of features by their magnetic anomalies, and second, the extent to which we can interpret eventual patterning of features and "empty" areas in terms of functional specialization. In Sect. 5, we have shown that 


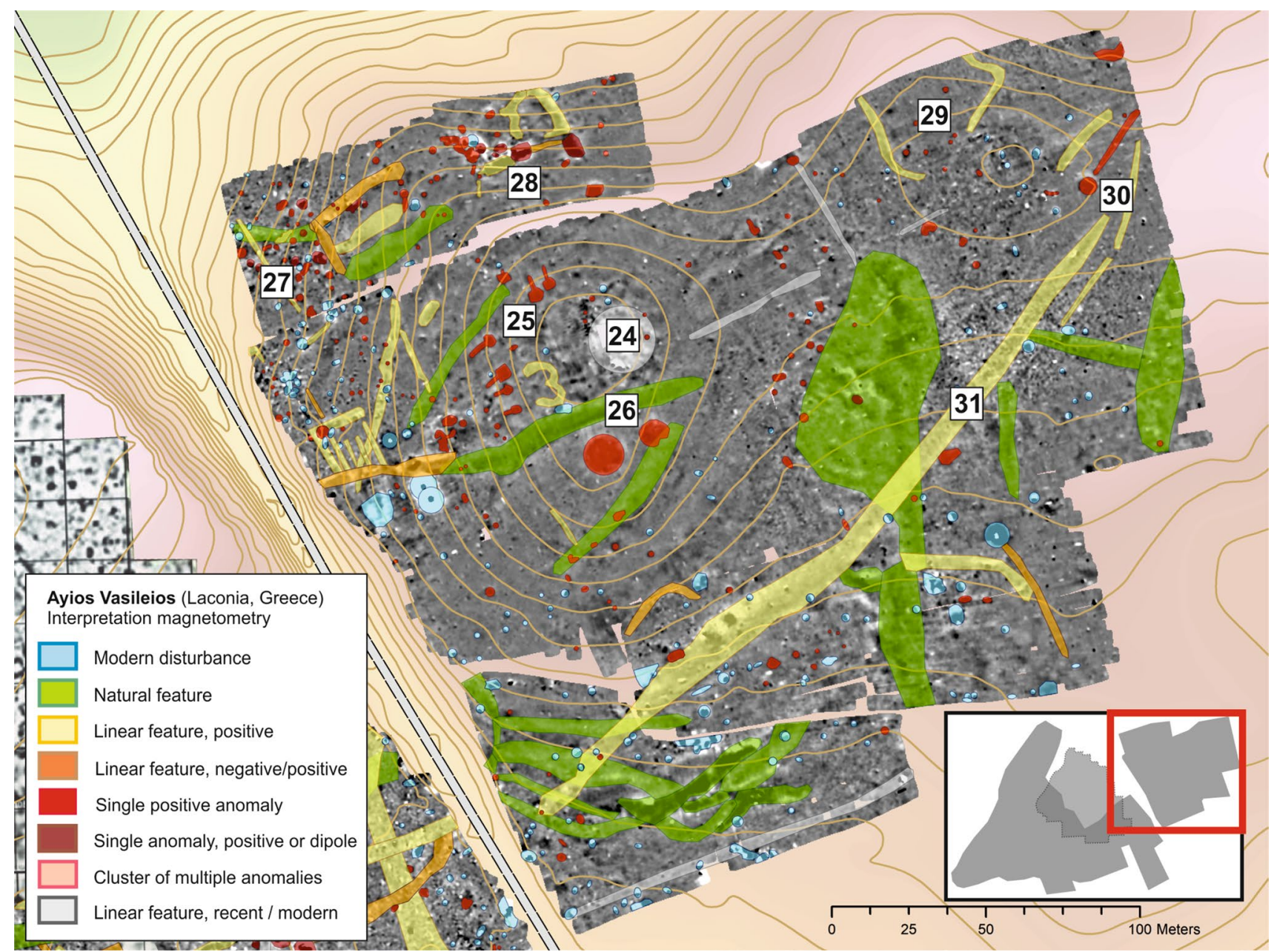

Fig. 8 Ayios Vasileios, Laconia, Greece. Interpretation of magnetometry results in the NE part of the site. Features discussed in the text are numbered

we can indeed do so by pairing the detailed interpretation of single or clustered magnetic anomalies with other levels of interdisciplinary information, including the surface record, the excavations, and wider scholarship on the Mycenaean world. We now have to discuss these results against our two central research questions: firstly, what is the extent of the palatial settlement, and secondly, can we identify evidence for functional specialization, spatial organization, and zoning? Moreover, we have to situate our findings in the framework of existing scholarship on Mycenaean palatial settlements.

\section{The extent of the palatial settlement}

The magnetometry data of Ayios Vasileios allows us to distinguish areas of human occupation versus "empty" zones where we do not recognize human impact. This patterning can be used to draw a preliminary border of the settlement at its maximum extent (Fig. 9). This conclusion is also supported by the surface record (Wiersma et al. 2021, Wiersma et al. in press). The settlement extent, as reconstructed here, belongs presumably to the peak of the settlement in the LH IIIA-early LH IIIB period; the further study of the surface material provided by the pedestrian survey may add further detail on the growth of the settlement during its early phases and perhaps its contraction after the destruction of the palatial complex.

Based on the geophysical data, we distinguish between a densely built central palatial complex of ca. 2,2 hectare at the core of the site. This is situated on the summit of Hill 1, near the chapel, and was already mapped by Tsokas et al. and Polymenakos (gray dotted line in Fig. 9). The North Cemetery, also on the top of Hill 1, is located just outside the settlement, as is common for the Early Mycenaean period. A built zone extends beyond the palatial complex on the gentle slope towards the south (gray dashed line in Fig. 9). In the south, a large wall of max. $7 \mathrm{~m}$ thick [feature 17] may be a boundary of sorts, but 


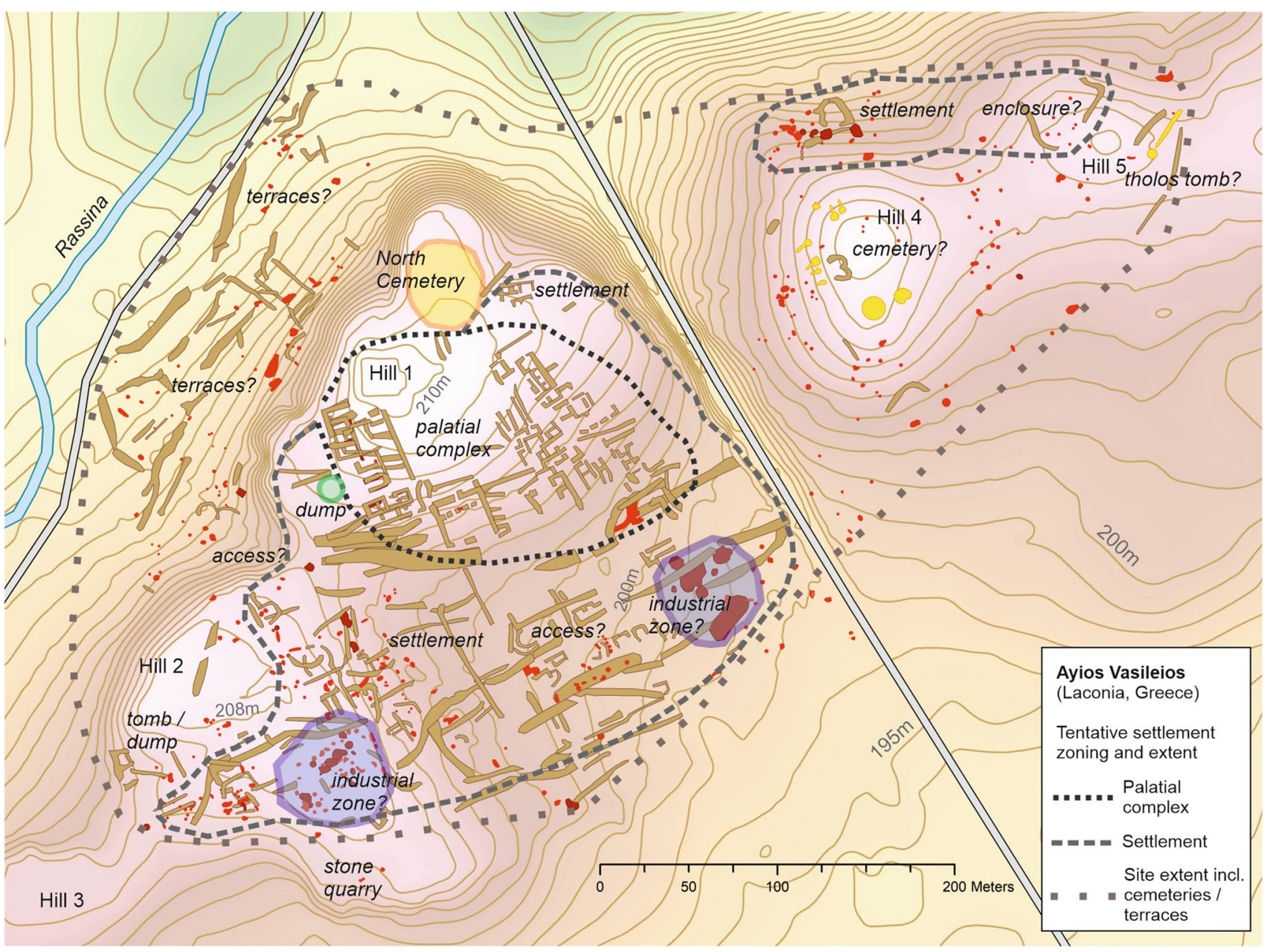

Fig. 9 Ayios Vasileios, Laconia, Greece. Functional areas and site extent as reconstructed on the basis of the 2018 magnetometry data and the RES surveys of Tsokas et al. (2010; 2012a) and Polymenakos (2012a, b). Architectural traces are indicated in brown, crafts areas in gray, burials in yellow

the earlier phases of the period were located closer to the inhabited area. Finally, if our interpretation of the features on the ridge east of the Sparta-Gytheio road as another cemetery (consisting of both chamber and tholos tombs?) is correct, the settlement seems to be contained among burial zones. However, it should be kept in mind that there are also traces of Mycenaean, and possibly later habitation in this area, as well as evidence for a possible enclosure and pathways whose date remains uncertain (gray dashed line in Fig. 9).

The slopes north of Hills 1 and 2 were used intensively, but it is difficult to characterize these areas on the basis of the magnetometry data alone. We have detected linear features which may be explained as a terrace system, but there are also clusters of smaller anomalies which could imply that the area was inhabited-although the date of habitation cannot of course be established. The results of the pedestrian survey may help here; indeed, Mycenaean pottery is found ing Mycenaean practice, as the extramural cemeteries in 
here, but in relatively low densities. This may support the inference that this area was used for agricultural purposes, although other functions cannot be excluded.

The total extent of the palatial settlement including the burials in the east, terraces in the north, and low-impact areas on Hills 2, 4, and 5 covers ca. 17 hectares (widely dotted line in Fig. 9); this figure is supported by the surface material as well (Wiersma et al. 2021: 172). The settled zone of the site covers ca. 9 hectares (palatial complex plus surrounding settlement and workshop areas; dashed line in Fig. 9). These results are admittedly surprising, as this size is rather small for a Mycenaean palatial town. However, the limited dimensions of Ayios Vasileios, as inferred from the magnetometry and the surface data, underline the variation within this site type if we, for instance, compare Ayios Vasileios and the comparable Pylos with much larger Mycenae (see above). Moreover, it highlights the need for explanatory models which take into account regional and socio-political variability in the Mycenaean world (Voutsaki et al. 2019).

\section{Indications of functional specialization and zoning}

The layout of Mycenaean palatial towns expresses the complex social and political systems of Late Bronze Age Greece. We explored the possibility to reconstruct typical elements of Mycenaean spatial organization at Ayios Vasileios through the large-scale magnetometer survey. Such elements include regulated access to the palatial complex, the presence of a settlement surrounding it, separate funerary, and perhaps also industrial zones. The magnetometry data shows evidence for all four characteristics, which we will expand on below.

The previous geophysical work by Tsokas and Polymenakos already suggested that space in the palatial complex on Hill 1 was highly organized. The RES surveys revealed a densely built urban grid (as also in Dimini: Adrymi-Sismani 2016). Buildings are constructed closely to one another and share the same orientation, while movement seems to be channeled through narrow passages between them. Although some caution is needed in interpreting the site layout because of the Byzantine occupation of the hilltop during which some of the Mycenaean walls were reused, the excavations so far have confirmed the Mycenaean date of key buildings. Resistivity mapping suggested that there may have been some kind of demarcation between the palace and the North Cemetery in the form of a linear feature oriented SW to NE (visible in Polymenakos 2019: 6, Fig. 4), while the excavation revealed a possible "platform" at the point of access from the settlement (Voutsaki et al. 2021). The orientation and dimensions of the resistivity features in the general area of the North Cemetery are different from those of the buildings in the inhabited site core, which can be explained by the use and re-use of large cavities in the conglomerate bedrock and gravel layers for burial (Moutafi and Voutsaki 2016; Polymenakos 2019).

The magnetometer data shows clear indications for the demarcation of the palatial complex on Hill 1. In the northwestern corner of the palatial complex, just southwest of the chapel, an area with magnetic anomalies with high amplitudes coincides with the westernmost buildings mapped by RES. As mentioned above, the strong magnetic anomalies are demarcated to the south by three features of several meters wide, parallel to the slope contours [feature 2], which we tentatively interpret as terraces. If these are indeed contemporary with the buildings in the site core, they constitute a pronounced internal spatial division. Possible traces of a gate [18] controlling the access to the palatial complex are located some $50 \mathrm{~m}$ to the south of these terraces. Further evidence for a terrace system comes from the excavation (see above). Access to the site core from the north may also have been regulated by a terrace system [feature 4].

A road system along which such access would have been guided is more difficult to distinguish. Neither on the north slope nor on the gentler southern slopes do we see clear pathways leading to gates accessing the palatial complex. However, there are two striking linear features which we tentatively interpret as trackways connected to the palace. One runs N-S just east of the anomaly cluster [23] and may partially be destroyed by the modern road cut. The other one runs SW-NE on the eastern ridge on the other side of the road, linking the palatial settlement to the area we interpreted as a cemetery [25], and specifically to the possible tholos tomb [30] on Hill 5. While we cannot date either of these possible trackways, their location and orientation do appear to link them to the settlement.

To the south of the palatial complex, we have detected multiple features which testify to the dense occupation of the surrounding settlement. A set of long features which we have interpreted as walls [17] may be expressions of spatial demarcation and control. Their magnetic amplitudes are relatively low as compared to the burnt features in the site core: these linear anomalies appear to be produced by contrasts in building materials rather than heating, but this should be confirmed by additional research.

North of these features, the intensity of human activity can be inferred from the density of magnetic anomalies. These include linear features which we attribute to buildings, although in this area we cannot distinguish organized patterns of architectural planning. There are also dense anthropogenic traces south of the walls [17], including the cluster of features which we interpreted as buildings [20] and the areas which we have tentatively identified as workshops [22] and [23]. These traces stop approximately $75 \mathrm{~m}$ south of the walls [17], and the fields beyond are distinctly empty, indicating the southern limits of the settlement. The combined 
information from the RES and magnetometer surveys allow us now to distinguish between, on the one hand, a dense rectangular grid in the site core bounded to the south by a system of walls and perhaps an entrance through a gate [18], and, on the other, a less dense and more heterogeneous zone, ca. $75 \mathrm{~m}$ wide, further south with features of various magnetic signatures. To the north of the site core, the site also seems bounded by a series of terraces [4], but here, the situation is less clear because of later occupation along the steep northern slopes of Hill 1 [5].

While our reconstruction of zones of activity inside the built-up zone should be considered tentative, as we have pointed out above in the discussion about the extent of the settlement, we can certainly reconstruct a burial zone surrounding the settlement area, with ascertained or possible cemeteries to the north, southwest, and east of the site.

We may also be able to detect different kinds of activities on the basis of the magnetometer survey data. There are a number of magnetic features in the palatial settlement which hint at the existence of special activity areas. At the moment, their chronological link with the Mycenaean occupation is not verified, but the association may be strengthened by the presence of surface artifacts recorded by the pedestrian survey. Single features recognized by magnetic anomalies with high amplitudes in the SE [21] and a cluster of strong dipole anomalies in the SW [15] are likely to be caused by heating related to productive activities, an interpretation supported by metal slags found on the surface during the magnetometer survey in the SE zone. We therefore suggested that these areas may be industrial zones. The aligned strong dipole anomalies in an area of intense human impact in the SW [15] have also been tentatively identified as workshops with kilns. Both of these areas are situated away from the palatial complex, on the southern limits of the surrounding settlement.

So far, there have been few systematic studies of the recognition of prehistoric workshop spaces in geophysical data, other than iron production which is obviously highly susceptible to magnetic prospection (Stamnes et al. 2019). Magnetometry is especially suited to detect pyrotechnological production sites using the effects of thermoremanent magnetism found in strongly heated materials, but also the magnetic properties of some by-products such as slags. We cannot enter here the debate about the degree of specialization or the scale of production in the Mycenaean world, but we can make a few remarks about the size and nature of these features and about their location in the periphery of the settlement.

At this point, we cannot establish what was produced in the two clusters of highly magnetic features on the southern outskirts of Ayios Vasileios, but it should be pointed out that the facilities are rather large. The cluster of aligned dipole anomalies in the SW [15] has typical shapes and dimensions for pottery kilns. The anomalies are ca. $2 \mathrm{~m}$ wide and $5 \mathrm{~m}$ in length, yet the actual dimensions of the archaeological contexts producing the magnetic amplitudes may be smaller. Although at the moment we cannot date these features, their dimensions are typical for Late Bronze Age pottery kilns of which several examples have been excavated; for instance, in Berbati in the Argolid (Schallin 1997). Mycenaean pottery kilns are indeed known from palatial contexts, such as the poorly documented specimen in the Middle Citadel at Tiryns (Dragendorff 1913: 339-341; Müller 1930: 113) and the LH IIIC kiln attached to the Cyclopean walls of the Lower Citadel of Tiryns (which dates, however, to the period after the destruction of the palaces; Kilian et al. 1981: 184-185; Rahmstorf 2015). The latter was associated with a series of refuse pits filled with ash and misfired pieces up to 6-12 m from the kiln. Likewise, the cluster of aligned dipole anomalies at Ayios Vasileios [15] are situated in a zone with a large number of pit-like features which may be related to industrial waste.

The two clusters of high amplitude magnetic anomalies are evidently caused by large, fixed facilities that could be associated with primary production. The weaker magnetic features nearby may be related to associated traces such as clay pits, water pits, and refuse heaps. The dimensions of both clusters suggest that they were large-scale, permanent/ specialized for the production of pottery and/or metals. The clusters are set apart with a distance of ca. $230 \mathrm{~m}$ between them. If they are indeed contemporary - and this cannot be established without further invasive work-this may suggest that pyrotechnologies were not concentrated in one area. The morphology of the magnetic features at Ayios Vasileios suggests that these may have been different types of kilns, each one placed on the outskirts of the palatial settlement. If we accept the presence of two large productive zones with a certain fire hazard, this may explain why this part of the settlement was not as densely built as the site core. We need to repeat, however, that our reconstructions remain hypothetical and can only be corroborated by means of coring or further excavation.

\section{Conclusions}

In this article, we problematized the archaeological interpretation of non-invasive geophysical prospection data and sought an explicit interdisciplinary dialogue in the interpretation of new magnetometer survey data of a Mycenean palatial settlement. The discussion highlights the limitations to our non-invasive approach, the many open questions surrounding the spatial organization of Mycenaean palatial towns, but also the often very detailed knowledge of various aspects of this site type. Our work at Ayios Vasileios is a unique case of a large-scale magnetometry survey on a short-lived, well-preserved Mycenaean palatial settlement. 
With few and limited previous magnetometer surveys on similar archaeological contexts to support our interpretations, much of the research presented here is pioneering work. In this light, the full 20-hectare coverage under the olive canopy deserves to be highlighted. The challenges of geophysical surveys in olive groves are not to be underestimated, as anyone who as ever attempted one will agree. The successful large-scale coverage of Ayios Vasileios thus opens up new possibilities for the study of such sites.

Our choice for magnetometry may seem peculiar regarding the spectacular results of RES on the site core, but was made deliberately. We wanted to be able to cover a large area within a limited budget and a limited amount of time; we would not have been able to cover 20 hectares with any other technique. Moreover, we were interested not only in walls and other structural remains, but also in other expressions of human activity like pits, ditches, and fireplaces for which we expected a detectable magnetic contrast. From the tests by Tsokas et al. (2010), we knew that such contrasts exist, plus we knew from the excavated contexts that the burial depth of potential features would probably not be very large. In hindsight, it would have been interesting to resurvey Tsokas' magnetometer test areas and integrate them in a larger survey, knowing now that these tests were placed on the border of the North Cemetery. The complex reuse of natural and artificial cavities here made the interpretation of these test data problematic and in part led to the selection of RES for further work (Polymenakos 2019). Perhaps there will be an opportunity to expand our survey approach in the future.

The availability of different geophysical data collected earlier in the palatial complex was a positive factor for our present work. The partial overlap of the magnetometry and RES surveys strengthens our interpretations of specific linear features in and near the site core. Indeed, data interpretation remains one of the biggest challenges for geophysical surveys, even more so in prehistoric contexts. Moreover, no geophysical technique is able to detect all buried traces of human activity, nor to date the ones detected.

We interpreted the magnetometer survey data using four levels of interdisciplinary information: first, the shape, size, and amplitude of magnetic anomalies caused by specific features; second, information on buildings and architectural orientation from previous geophysical work at the site; third, the preliminary conclusions of the pedestrian survey; and lastly the general knowledge derived from excavations at Ayios Vasileios and other Mycenaean sites. We have aimed to keep these four levels separate and be explicit in how we used them, though they sometimes overlap and inform each other. Obviously, the future application of more techniques in tandem with the targeted verification of detected features (coring, test pitting) would certainly enhance our understanding of the site; unfortunately, we were not given the permission to conduct such work. We are aware that if such work is ever undertaken in the future, it may support, but also undermine the interpretations presented here. In the meantime, we emphasize the need for more research on the material properties of archaeological materials related to geophysical prospection and contexts to enhance their detectability and interpretation. But we also emphasize the need for a close collaboration between geophysicists and archaeologists, such as in our project, to be able to provide a more contextualized interpretation of geophysical features.

We are confident that the research presented here contributes to the wider application of magnetometry in the study of the spatial organization of prehistoric urban contexts. We were able to estimate the extent of the site and suggest different occupation zones by means of the explicit use of the above-mentioned four levels of information. Functional zones were mostly recognized through the high amplitudes and density of magnetic anomalies rather than the identification of single features, but the contrast with the relatively quiet natural background as seen to the south of the settlement makes the demarcation quite certain. Following the same reasoning, we are able to identify areas of more ephemeral human impact which did not involve or leave behind any artifacts. The presence of highly magnetic features to the south of the site core, which we tentatively interpret as the fixed installations of different pyrotechnological crafts, may suggest a degree of functional specialization (see Sect. 6). Moreover, we were able to identify specific activities on the ridge to the east of the Sparta-Gytheio road, where occupation was notably less dense.

Finally, our focus on indications of specific characteristics of palatial sites has proven to be useful and allows us to place Ayios Vasileios in the wider context of the Mycenaean world. Geophysics has helped us reconstruct a dense urban grid and detect monumental complexes, but also reconstruct, albeit tentatively, the spatial organization and functional specialization of different areas inside, at the margins, and outside of the inhabited area. This approach takes the use of the geophysical surveys beyond that of a simple mapping tool or guidance for future excavations. While a detailed spatial analysis of the palace similar to Benech's approach at Dura-Europos (2007) remains challenging on the basis of the data presented here, we emphasize the contribution of largescale, non-invasive prospection in a more holistic approach to this type of site and its surroundings. Using geophysical data to look beyond the architecture of the palatial settlement puts the spotlight on a broad range of human activity in and around complex, centralized, and multi-functional prehistoric towns.

Acknowledgements The research presented in this article is generously funded by the Gerda Henkel Stiftung (post-doctoral grant AZ51 F15). We thank Ms. Adamantia Vasilogamvrou, the director of the Ayios Vasileios Project, as well as the Archaeological Society at Athens and the Laconia Directorate of Prehistoric and Classical Antiquities 
for permissions to prospect the area. We would like to thank Corien Wiersma and the participants of the Ayios Vasileios Survey for their support, and for sharing their data with us. We thank the two anonymous reviewers for their useful comments, and are very grateful to Todd Whitelaw who commented on an early draft of this article. Extra thanks are due to the municipality and inhabitants of Xirokambi who welcomed us during our fieldwork, especially to Christos Giannakas who made us appreciate the olive trees after all.

Author contribution All authors contributed to the research conception and design. Data collection, processing, and interpretation were performed by Wieke de Neef, Burkart Ullrich, and Ronald Freibothe. The first draft of the manuscript was written by Wieke de Neef; all authors commented on previous versions of the manuscript. All authors read and approved the final manuscript.

Funding The research leading to these results received funding from the Gerda Henkel Foundation (Germany) under Grant Agreement No. AZ51 F15.

Data availability All data generated and analyzed during this study are included in this article.

Code availability Code availability does not apply.

\section{Declarations}

Conflict of interest The authors declare no competing interests.

Open Access This article is licensed under a Creative Commons Attribution 4.0 International License, which permits use, sharing, adaptation, distribution and reproduction in any medium or format, as long as you give appropriate credit to the original author(s) and the source, provide a link to the Creative Commons licence, and indicate if changes were made. The images or other third party material in this article are included in the article's Creative Commons licence, unless indicated otherwise in a credit line to the material. If material is not included in the article's Creative Commons licence and your intended use is not permitted by statutory regulation or exceeds the permitted use, you will need to obtain permission directly from the copyright holder. To view a copy of this licence, visit http://creativecommons.org/licenses/by/4.0/.

\section{References}

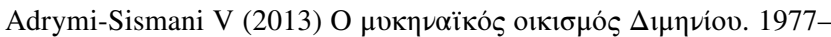
1997. $20 \chi \rho o ́ \nu 1 \alpha \alpha \nu \alpha \sigma \kappa \alpha \varphi \omega ́ \nu$. Archaeological Institute of Thessalian Studies. Volos, Greek Ministry of Culture.

Adrymi-Sismani V (2016) Dimini: an urban settlement of the Late Bronze Age in the Pagasitic Gulf. In: Driessen J (ed) Ra-pi-ne-u: Studies on the Mycenaean World offered to Robert Laffineur for his 70th Birthday, Aegis 10. Presses Universitaires de Louvain, Louvain-la-Neuve, pp 39-61

Aravantinos V, Vasilogamvrou A (2012) The first Linear B documents from Ayios Vasileios (Laconia). In: Carlier P, De Lamberterie C, Egetmeyer M, Guilleux N, Rougemont F, Zurbach J (eds), Études mycéniennes 2010: Actes du XIIIe colloque international sur les textes égéens, Sèvres, Paris, Nanterre, 20-23 septembre 2010, Biblioteca di "Pasiphae". Collana di Filologia e Antichità egee 10. Fabrizio Serra, Pisa/Rome, pp 41-54.

Banou E (1996) Beitrag zum Studium Lakoniens in der Mykenischen Zeit. Tuduv, München
Bendall LM (2003) A reconsideration of the northeastern building at Pylos: evidence for a Mycenaean Redistributive Center. Am J Archaeol 107(2):181-231

Benech C (2007) New approach to the study of city planning and domestic dwellings in the ancient Near East. Archaeol Prospect 14(2):87-103

Bennet J (2007) Pylos. The expansion of a Mycenaean palatial center. In: Galaty ML, Parkinson WA (eds) Rethinking Mycenaean Palaces II. University of California Press, Berkeley, pp 29-39

Blegen CW, Rawson M (1966) The Palace of Nestor at Pylos in Western Messenia, vol I. The buildings and their contents. Princeton University Press, Princeton

Blegen CW, Rawson M, Taylour WD, Donovan WP (1973) The Palace of Nestor at Pylos in Western Messenia. Vol. III: Acropolis and Lower Town; Tholoi, Grave Circle, and Chamber Tombs; Discoveries Outside the Citadel. University of Cincinnati Press, Cincinnati

Boyd M (2016) The geophysical survey: imagining the architecture and settlement structure of Iklaina. In: Cosmopoulos M (ed), The Political Geography of a Mycenaean district. The Archaeological Survey at Iklaina. The Archaeological Society at Athens Library no. 306. The Archaeological Society at Athens, Athens, pp 39-65

Brysbaert A (2014) Talking Shop. Multicraft workshop materials and architecture in prehistoric Tiryns, Greece. In: Rebay-Salisbury K, Brysbaert A, Foxhall L (eds) Material Crossovers: knowledge networks and the movement of technological knowledge between craft traditions. Routledge, London, pp 37-61

Chapman J, Videiko M, Gaydarska B, Burdo N, Hale D, Villis R, Swann N. Thomas N, Edwards P, Blair A, Hayes A (2014). The planning of the earliest European proto-towns: a new geophysical plan of the Trypillia mega-site of Nebelivka, Kirovograd Domain, Ukraine. Antiquity 88 (339) online project gallery: http://antiq uity.ac.uk/projgall/chapman339/. Accessed 2 Aug 2021

Corsi C, Johnson P, Vermeulen F (2012) A geomagnetic survey of Ammaia: a contribution to understanding Roman urbanism in Lusitania. Journal of Roman Archaeology 25:121-145. https:// doi.org/10.1017/S1047759400001161

Cosmopoulos MB (ed) (2016) The political geography of a Mycenaean district: the archaeological survey at Iklaina. The Archaeological Society at Athens Library 306. The Archaeological Society at Athens, Athens.

Davis JL (1998) Sandy Pylos: an archaeological history from Nestor to Navarino. University of Texas Press, Princeton

Davis JL, Alcock SE, Bennet J, Lolos YG, Shelmerdine CW (2017) The Pylos regional archaeological project, Part I: Overview and the Archaeological Survey. In: Davis JL, Bennet J (eds) The Pylos Regional Archaeological Project: A Retrospective. American School of Classical Studies in Athens, Athens, pp 63-151

Dragendorff H (1913) Tiryns. Vorbericht über die Ausgrabungen 1913. Mitteilungen Des Deutschen Archäologischen Instituts, Athenische Abteilung 1913:329-354

French EB (2002) Mycenae, Agamemnon's capital: the site in its setting. Tempus, Stroud, Charleston, SC.

Gallo D, Ciminale M, Pallara M, Laviano R (2011) Susceptibility measurements, optical and X-ray analysis to explain the origin of archaeological magnetic anomalies in Tavoliere lowland (Southern Italy). J Archaeol Sci 38(2):399-407

Hitchcock L (2018) Vapheio-Palaiopyrgi survey project 2017. The Australian Archaeological Institute at Athens Bulletin 14:14-15

Hope Simpson R (2009) The Mycenaean settlements in the Sparta plain and the ancient traditions. Studies in Mediterranean Archaeology 51:315-335

Hope Simpson R, Hagel DK (2006) Mycenaean fortifications, highways, dams and canals. Paul Aström Vorlag, Stockholm. 
Jones RE (2009) Proton magnetometer survey at the Menelaion and environs. In: Catling H (ed) Sparta, Menelaion I: The Bronze Age. Supplementary Series, Volume 45. The British School at Athens, London, pp 176-179

Kardamaki E (2017) The Late Helladic IIB to IIIA2 pottery sequence from the Mycenaean palace at Ayios Vasileios, Laconia. Archaeologica Austriaca 101:73-142

Kilian K, Podzuweit C, Weisshaar HJ (1981) Ausgrabungen in Tiryns 1978-1979. Archäologischer Anzeiger Berlin 2:149-256

Lane MF, Horsley TJ, Charami A, Bittner WS (2016) Archaeological geophysics of a Bronze Age agricultural landscape: the AROURA Project, central mainland Greece. J Field Archaeol 41(3):271-296

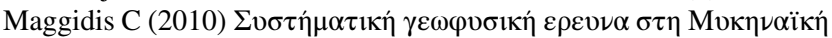
$\alpha \kappa \rho о \pi \circ \lambda \eta \tau$ оo $\Gamma \lambda \alpha$. Praktika Tes En Athenais Archaeologikes Etaireias 165:81-89

Maggidis C, Stamos A (2006) Detecting Mycenae. Systematic remote sensing survey in the 'Lower City': towards the discovery of the Mycenaean settlement outside the citadel. In: Campana S, Forte M (eds) From Space to Place. $2^{\text {nd }}$ International Conference on Remote Sensing in archaeology, CNR, Rome, Italy, 4-7 December 2007. BAR International Series 1568. Archaeopress, Oxford, pp $157-166$

Moutafi I, Voutsaki S (2016) Commingled burials and shifting notions of the self at the onset of the Mycenaean era (1700-1500 BCE): the case of the Ayios Vasileios North Cemetery, Laconia. J Archaeol Sci Rep 10:780-790

Müller K (1930) Tiryns III: Die Architektur der Burg und des Palastes. Benno Filser Verlag, Augsburg

Niemeier W-D (1997) The Mycenaean potter's quarter at Miletus. In: Laffineur R, Betancourt PP (eds) TEHNI: Craftsmen, Craftswomen and Craftsmanship in the Aegean Bronze Age. Proceedings of the 6th International Aegean Conference, Philadelphia, Temple University, 18-21 April 1996. Aegaeum 16. Université de Liège, University of Texas at Austin, Liège, Austin, pp 347-352

Pantou PA (2010) Mycenaean Dimini in context: investigating regional variability and socioeconomic complexities in Late Bronze Age Greece. Am J Archaeol 114(3):381-401

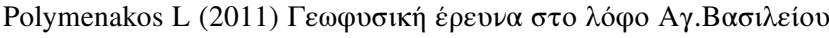

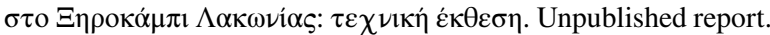

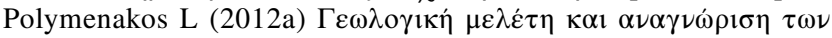

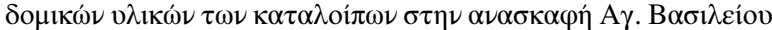

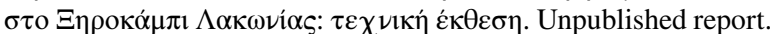

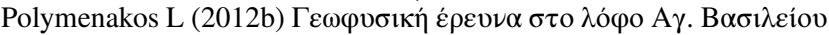

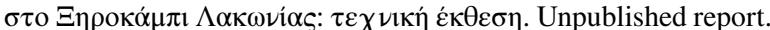

Polymenakos L (2013) Geophysical investigation (cemetery site) at Ayios Vasileios hill, Xirokampi, Lakonia, Greece: Technical report (2013). Unpublished report.

Polymenakos L (2014) Geophysical investigation (cemetery site) at Ayios Vasileios hill, Xirokampi, Lakonia, Greece: Technical report (2014). Unpublished report.

Polymenakos L (2019) Searching for prehistoric small-sized graves in complex geoarchaeological conditions: Ayios Vasilios North Cemetery (Peloponnese, Greece). J Archaeol Sci Rep 24:1-15

Pullen D (2013) Crafts, specialists, and markets in Mycenaean Greece. Exchanging the Mycenaean economy. American Journal of Archaeology 117 (3):437-445.

Rahmstorf L (2015) Workshop activities and pyrotechnology at Mycenaean Tiryns. In: Schallin AL, Tournavitou I (eds) Mycenaeans up-to-date. The archaeology of the NE Peloponnese - current concepts and new directions. Swedish Institute at Athens, Athens, pp 143-149.

Sarris A, Adrymi-Sismani V, Topouzi S, Soetens S, Triantafyllidis F, Kevgas V, Karathanasis Ch, Giourou A, Tzaneteas K, Mavroudhis Th, Karimalis K, Karimali E, Papadaki A, Kritikakis G (2002) Geophysical Prospection in Mycenaean Dimini, Magnesia (Greece). In: Proceedings of 4th International Conference on
Computer Applications and Quantitative Methods in Archaeology (CAA 2002). Austrian Academy of Sciences, Vienna, pp 67-83

Schallin AL (1997) The Late Bronze Age potter's workshop at Mastos in the Berbati Valley. In: Gillis C, Risberg C, Sjöberg B (eds) Trade and Production in Premonetary Greece: Production and the Craftsman. Proceedings of the 4th and 5th International Workshops. Paul Aströms Forlag, Stockholm, pp 73-88.

Seren S, Eder-Hinterleitner A, Neubauer W, Groh S (2004) Combined high-resolution magnetics and GPR surveys of the roman town of Flavia Solva. Near Surface Geophysics 2(2):63-68

Spyropoulos TG (2013) $\Lambda \alpha \kappa \varepsilon \delta \alpha i \mu \omega \nu$. Vols. I-III. Kardamitsas, Athens. Stamnes AA, Stenvik LF, Risbøl O (2019) The use of LiDAR and geophysical methods for locating and investigating prehistoric iron production sites in Scandinavia. In: Stamnes AA, Risbøl O, Stenvik LF (eds) Early iron production by modern remote sensing technologies, Transactions of The Royal Norwegian Society of Sciences and Letters 2. DKNVS, Oslo, pp 5-15

Tsokas GN, Vargemezis G, Tsourlos P, Stampolidis A, Di Fiore B, Stefan CD, Florin Garbacea G, Stefan MM (2010) Geophysical investigations at the Agios Vasileios hill south of Sparta. Unpublished internal report, University of Thessaloniki

Tsokas GN, Stampolidis A, Di Fiore B,Vasilogamvrou A (2012a) Geophysical investigations at Agios Vassileios Hill South of

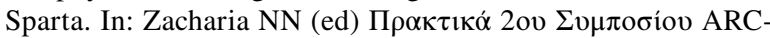

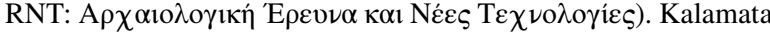
Laboratory for Archaeometry, Kalamata, pp 11-26.

Tsokas GN, Van de Moortel A, Tsourlos PI, Stampolidis A, Vargemezis G, Zahou E (2012b) Geophysical survey as an aid to excavation at Mitrou: A preliminary report. Hesperia 81(3):383-432

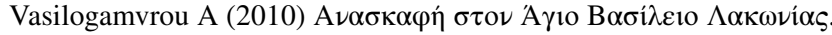
Praktika Tes En Athenais Archaeologikes Etaireias 165:65-80

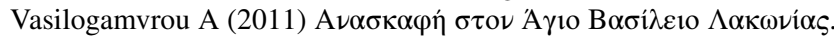
Praktika Tes En Athenais Archaeologikes Etaireias 166:59-68

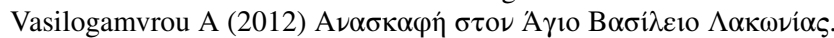
Praktika Tes En Athenais Archaeologikes Etaireias 167:63-76

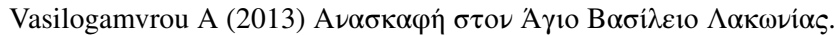
Praktika Tes En Athenais Archaeologikes Etaireias 168:97-116

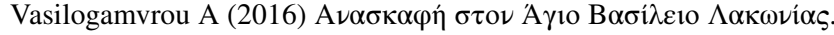
Praktika Tes En Athenais Archaeologikes Etaireias 171:131-181

Verdonck L, Launaro A, Vermeulen F, Millett M (2020) Ground-penetrating radar survey at Falerii Novi: a new approach to the study of Roman cities. Antiquity 94(375):705-723

Voutsaki S (2001) Economic control, power and prestige in the Mycenaean world: the archaeological evidence. In: Voutsaki S, Killen $\mathbf{J}$ (eds) Economy and Politics in the Mycenaean Palace States. Cambridge Philological Society, Cambridge, pp 195-213

Voutsaki S, Wiersma CW, De Neef W, Vasilogamvrou A (2019) The Ayios Vasileios Survey Project (Laconia, Greece): questions, aims and methods. Journal of Greek Archaeology 4:67-95

Voutsaki S, Hachtmann V, Moutafi I (2021) Space, place and social structure in the North Cemetery, Ayios Vasilios. In: Eder B, Zavadil M (eds) (Social) place and space in early Mycenaean Greece. Discussions in Mycenaean Archaeology. Austrian Academy of Sciences, Vienna, pp 323-340.

Waterhouse H, Hope Simpson R (1960) Prehistoric Laconia: Part I. Annual of the British School at Athens 55:67-107

Whitelaw TM (2017) The development and character of urban communities in prehistoric Crete in their regional context: a preliminary study. In: Letesson Q, Knappett C (eds) Minoan Architecture and Urbanism. New Perspectives on an Ancient Built Environment. Oxford University Press, Oxford, pp 114-180

Wiersma CW, De Neef W, Voutsaki S, Vasilogamvrou A (2021) The Ayios Vasilios Survey Project. Preliminary Results. In: Zymi E, Karapanagiotou M, Xanthopoulou (eds) Proceedings of Archaeological Research in the Peloponnese II. University of Peloponnese at Kalamata, Kalamata, pp 167-177 
Wiersma CW, De Neef W, Voutsaki S, Vasilogamvrou, A (in press) The Ayios Vasileios survey project. A preliminary outline of the habitation history and size of Ayios Vasileios compared to other palatial settlements. In: Wiersma CW, Tsouli M (eds) Middle and Late Helladic Laconia. Competing principalities? Sidestone Press, Leiden
Zangger E, Timpson ME, Yazvenko SB, Kuhnke F, Knauss J (1997) The Pylos Regional Archaeological Project. Part II: landscape evolution and site preservation. Hesperia 66(4):549-641

Publisher's note Springer Nature remains neutral with regard to jurisdictional claims in published maps and institutional affiliations. 